\title{
Critical Tests of Multiple Theories of Cultures' Consequences
}

\section{Comparing the Usefulness of Models by Hofstede, Inglehart and Baker, Schwartz, Steenkamp, and GDP and Distance for Explaining Overseas Tourism Behavior}

\author{
Shih-Yun Hsu, Asia University \\ Arch G. Woodside, Boston College \\ Roger Marshall, Auckland University of Technology
}

Submission: January 2012

Revision: April 2012

The authors are grateful to Dan Fesenmaier for comments and insights on an early revision of this article. Send correspondence to Shih-Yun Hsu, Asia University, Department of Leisure and Recreation Management, 500 Lioufeng Rd., Wufeng, Taichung 41354, Taiwan (shsu1@asia.edu.tw); Arch G. Woodside, Boston College, Department of Marketing, Carroll School of Management, 140 Commonwealth Avenue, Chestnut Hill, MA 02467, USA (arch.woodside@bc.edu); Roger Marshall, Auckland University of Technology, Department of Marketing, Private Bag 92006, Auckland 1142, New Zealand (roger.marshall@aut.ac.nz). 


\begin{abstract}
The study provides critical tests of the usefulness of four alternative theories, proposed by Hofstede, Inglehart, Schwartz, and Steenkamp, of national cultures’ influences for explaining consumers' consumption of international services. The study applies critical testing of these four theories in two research contexts: visiting Australia by holiday (vacation) travelers from 5 Asian and 5 Western nations and visiting the United States by holiday (vacation) travelers by visitors from 12 nations. The study is valuable in proposing and testing configurational perspectives of cultural influences rather than testing via "unpacking” the net effects of cultural dimensions separately. The findings indicate that cultural configurations do impact consumption behavior of international services beyond the influences of demographic conditions (distance and national wealth) and Schwartz's theory is useful in particular in explaining unique aspects of consuming international services.
\end{abstract}

Keywords: qualitative comparative analysis; fuzzy set; national culture; Hofstede; consumer behavior; international tourists. 


\section{Critical Tests of Multiple Theories of Cultures’ Consequences}

\section{Comparing the Usefulness of Models by Hofstede, Inglehart and Baker, Schwartz, Steenkamp, and GDP and Distance for Explaining Overseas Tourism Behavior}

\section{INTRODUCTION}

According to the World Tourism Organization (WTO), tourism, in 2008, has grown to become one of the top five industries with a market value of USD 946 billion, which accounts for $30 \%$ of world's exports of services. International tourist arrivals reached 924 million in 2008, and it is expected to increase to approximately 1.6 billion international arrivals by 2020 (WTO: 2009, 2001). Thus, understanding the different behaviors of tourists from various countries with different culture backgrounds is very important for countries’ tourism authorities in forming marketing plans and designing marketing strategies to attract international tourists from different countries.

National cultures represent complex values acting in concert rather than individual factors affecting behavior. For example, considering low, medium, and high levels of each of the four factors permits a property space (Lazarsfeld, 1937) analysis of 81 complex antecedent conditions or antecedent paths. While not all combinations occur among observable national cultures, data and research methods are available to permit the examination of how complex cultural conditional statements, beyond the view of individual cultural dimensions, affect the behavior of individuals or firms.

Prior researchers mainly focus on examining the individual influence of cultural dimensions on consumer behavior. For example, using Hofstede’s (1983) typology of four principal cross-cultural values including power distance, uncertainty avoidance, individualism, and masculinity, Lynn, Zinkhan, and Harris (1993) examine each value’s impact of tipping 
behavior. No attempt is made by Lynn et al. (1993) or other researchers to go beyond examining single cultural condition’s influence on individual or organizational behavior.

Therefore, the study proposes a theoretical approach for examining the influences of alternative configurations of national culture values on international tourist behaviors by examining the relevancy of configurations within four principal theories of national cultural influences on explaining human behavior (listed here by high-to-low citation impacts): Hofstede (1980), Schwartz (1994, 2006) , Inglehart and Baker (2000), and Steenkamp (2001). This paper includes conducting critical tests (Carlsmith, Ellsworth, \& Aronson, 1976) of these alternative theories of cultural consequences on international tourist behavior.

Following this introduction, section two reviews major cultural-value theories as well as qualitative comparative analysis. Section three explains the method of the study. Section four shows the analyses and findings. Section five includes conclusions, limitations of the study, and implications for theory and management practice.

\section{LITERATURE REVIEW}

One of the early definitions of culture is defined by Tylor in 1871, quoted by Soares, Farhangmehr and Shoham (2007), as "the complex whole which includes knowledge, belief, art, morals, custom and any other capabilities and habit acquired by man as a member of society.” More recently, scholars define culture as an interactive aggregate of common characteristics shared by the population of a nation (Clark, 1990; Hofstede, 1980, 2001; Steenkamp, 2001). Therefore, there is a need to study culture as configurations of antecedent conditions, instead of individual values one at a time, on consumer behavior.

However, the literature includes negative critiques about national cultural theories. Critics think that more than one culture exists in a nation. In addition, national is not the best unit 
of analysis for examining cultures. With globalization and advances in communication technology, people come from different cultural backgrounds travel and interact with each other easily so that the original cultures are contaminated and changed (Craig \& Douglas, 2006; Douglas \& Craig, 1997, 2006; McSweeney, 2002). However, these critics did not provide any empirical evidences.

On the contrary, many scholars perceive substantial relevancy in national cultural theories in explaining human behavior, including Clark (1990), Dewar \& Parker (1994), Hofstede (2002), Schwartz (2006), and Steenkamp (2001). They point out that delimiting subcultural groups in a nation is almost impossible. Nation is a meaningful proxy for culture because within country commonalities and between country differences do exist (Dewar \& Parker, 1994; Schwartz, 2006; Steenkamp, 2001). In addition, culture has centuries-old roots and thus changes very slowly. Therefore, a need still exists to study culture on national basis.

According to Taras's (2010) culture survey catalogue, a total of 154 instruments are publicly available for measuring culture. Among these cross-cultural theorists, Geert Hofstede, Ronald F. Inglehart, Shalom H. Schwartz, and Jan-Benedict E.M. Steenkamp are, perhaps, the four most widely cited authors of the cross-cultural studies in the Social Science Citation Index. This section first introduces their comprehensive national cultural frameworks used for crosscultural theorizing in empirical studies, then compares their works to find out the similarities among them, and concludes with the critical review of Hofstede's work to show that it is still the most important framework in social science.

\section{Hofstede's National Cultural Value Dimensions}

Hofstede (1980, 2001)'s well-known theory of national cultural value dimensions is based on the data collected in two survey rounds from IBM's international employee attitude 
survey program between 1967 and 1973. The data includes answers to more than 116,000 questionnaires from 72 different countries in 20 languages. However, the initial analysis is limited to the data from 40 countries due to the reason that some countries contain missing data in the occupational categories. Later, in 1982, the list of countries extends to 50 countries plus 3 regions (Hofstede, 1980, 2001).

In his book, Culture's consequences: International differences in work-related values, Hofstede (1980) identifies four national cultural dimensions, including power distance, uncertainty avoidance, individualism vs. collectivism, and masculinity vs. femininity. Hofstede’s four dimensions of national culture values are summarized as follows.

- Power distance measures the degree of inequality in power perceived by the less powerful member between a superior and a subordinate in a hierarchy. Inequality is a common phenomenon found in countries with high scores on the power distance index (PDI).

- Individualism measures the degree of independence in the way of how people work. Countries score high on the individualism index (IDV) are individualism countries, in which people like to act as individuals. On the contrary, countries scoring low on IDV are collectivism countries in which people like to act as members of group.

- Masculinity measures the degree of dominance of the masculine values in a country. The masculine values like assertiveness and competitiveness are dominant in countries with high scores on masculinity index (MAS). In contrast, the feminine values like nurturance and tenderness are dominant in countries with low MAS scores.

- Uncertainty avoidance measures the degree of comfortableness perceived by the populations of a culture in unstructured situations. People in countries with higher scores on the 
uncertainty avoidance index (UAI) feel more anxious and stressed when facing uncertain situations than those in countries with lower scores on UAI.

Hofstede’s national cultural framework may be the most influential conceptual foundation in cross-cultural studies (Fernandez, Carlson, Stepina, \& Nicholson, 1997) that his work has been cited 1,101 times during the years of 1987 and 1997 according to the Social Science Citation Index (Sivakumar \& Nakata, 2001). His framework is both conceptually and empirically important. Many similarities occur in different typologies of culture corresponding to his national value dimensions (Clark, 1990). In addition, his five dimensions are validated by 140 various survey and non-survey studies that compare between 5 and 39 countries (Hofstede, 2001).

\section{Inglehart's World Values}

Inglehart, Baker, and Norris (Inglehart \& Baker, 2000; Inglehart \& Norris, 2003) identify two value dimensions of cross-cultural variation through four waves of World Values Survey (WVS) from 1981 to 2001 to address issues in sociology about modernization. The WVS data are collected from interviewing an average of 1,400 respondents per country from 81 countries on all six inhabited continents contains more than $80 \%$ of the world's population. The two dimensions are summarized as follows.

- Traditional vs. secular-rational dimension concerns orientations towards authority. In traditional societies, people emphasize the importance of religion, nation, and family. On the other side, people in secular-rational societies do not think those are important.

- Survival vs. self-expression dimension concerns the relation between self and group. Survival values emphasize the importance of economic and physical security. In survival societies, people feel unhappy and insecure when facing unfamiliar things and changes. On 
the contrary, self-expression values emphasize subjective wellbeing and quality of life. In self-expression societies, people take survival for granted and they accept differences and changes.

Even though Inglehart's framework has not yet been applied as widely as Hofstede’s model in research areas, his model deserves to receive scholarly attention not only because of the sound methodology in his research, but also the extensive size and duration covered in his data collection.

\section{Schwartz's Cultural Value Orientations}

Schwartz (2006) validates three cultural value dimensions, which contains seven cultural value orientations, based on his findings analyzed from the data collected from a total of 73 countries via two different instruments: the Schwartz Value Survey (SVS) and the Portrait Values Questionnaire (PVQ). The SVS data was collected from schoolteachers and college students in 67 nations during the years of 1988 and 2000. The PVQ data was gathered from the European Social Survey (ESS) in 20 countries. Schwartz's seven cultural value orientations are summarized in three bipolar cultural value dimensions as follows.

- Autonomy vs. embeddedness emphasizes the relations between the individual and the group. In autonomy cultures, people are independent and unique. They are encouraged to express their own internal attributes, such as feelings, ideas, and preferences. There are two types of autonomy, including intellectual autonomy and affective autonomy. On the contrary, in embeddedness cultures, people are embedded in collectivity. They emphasize on maintaining the status quo and restraining actions that may disrupt group unity or the existing order. 
- Egalitarianism vs. hierarchy emphasizes people’s responsibilities attached to their roles and social resource allocation. In egalitarianism cultures, people are moral equals who have shared interests of committing to cooperate with others and considering the welfare of others. However, in hierarchy cultures, the unequal distribution of roles, power, and resources are legitimate. People play unequal roles in hierarchical systems that grant them different powers and responsibilities.

- Harmony vs. mastery emphasizes the way people manage to fit in the natural and social world. In harmony cultures, people understand and appreciate the world as it is and try to preserve it. However, in mastery cultures, people try to actively direct and change the surrounding environment in order to achieve their goals.

Unlike Hofstede and Inglehart's frameworks based on a posterior theorizing, Schwartz’s cultural value dimensions are based on a priori theorizing (Schwartz, 2006). In addition, his approach to view “cultural dimensions as forming an integrated, non-orthogonal system” distinguishes his interdependent dimensions from Hofstede and Inglehart’s orthogonal dimensions (Schwartz, 2006, p. 142). Although Schwartz's model is based on strong theoretical foundations with more updated data than Hofstede’s, his framework has not yet been applied widely (Steenkamp, 2001).

\section{Steenkamp’s National-Cultural Dimensions}

Steenkamp (2001) examines the two major cultural dimensions proposed by Hofstede and Schwartz, and comes up with the four comprehensive national-cultural dimensions by analyzing the national cultural ratings of the 24 countries included in both Hofstede and Schwartz's data sets. His four national-cultural dimensions are stated as follows. 
- Autonomy vs. collectivism dimension, consistent with both Hofstede’s individualism/collectivism dimension and Schwartz's autonomy/embeddedness dimension, deals with the relation between the individual and the group. Hofstede’s power distance also associates with this dimension to maintain the order in a society.

- Egalitarianism vs. hierarchy dimension, like Schwartz's egalitarianism/ hierarchy dimension, refers to how people consider the interests of others and cooperate in harmony with them.

- Mastery vs. nurturance dimension, similar to Hofstede’s masculinity/femininity and Schwartz's harmony/mastery, deals with how people fit into the social and natural environment and emphasizes on assertiveness and achievement.

- Uncertainty avoidance, also found in Hofstede's framework, refers to how people handle the uncertain situation.

Steenkamp reports that the first two dimensions correlate with each other while other correlations are negligible. The society that is high on conservatism tends to emphasize on hierarchy; on the other hand, the society that views an individual as an autonomous self is more likely to address the importance of egalitarianism in order to maintain the function of the society. Although Steenkamp’s national cultural dimensions are purely derived from Hofstede and Schwartz's data sets, his study undoubtedly shows the importance of their cultural theories by pointing out the commonalities between the two.

\section{Comparison of Hofstede, Inglehart, Schwartz, and Steenkamp's Value Dimensions}

Similarities appear in comparing Hofstede, Schwartz, Inglehart and Baker, and Steenkamp's value dimensions, although they conduct different research on different subjects with different methods in different periods of time. The table below shows that two, three, and 
four dimensions in Hofstede’s framework are closely associated with both Inglehart and Baker’s dimensions, all the three Schwartz's dimensions, and all the four Steenkamp's dimensions.

Table 1 here.

First, Hofstede’s power distance is similar to both Schwartz and Steenkamp’s egalitarianism/hierarchy and Inglehart and Baker’s traditional/secular-relational dimension because they all refer to the authority orientation. Second, Hofstede’s Individualism/collectivism overlaps with Schwartz's autonomy/embeddedness, Inglehart and Baker's survival/selfexpression and Steenkamp’s autonomy/collectivism due to their concerns about the relation between individual and group. Third, Hofstede’s masculinity/femininity, Schwartz’s harmony/mastery and Steenkamp’s mastery/nurturance are all associated with the relation to social and natural environment. Fourth, both Hofstede and Steenkamp come up with the uncertainty avoidance dimension that deals with how people handle the uncertain situation.

However, in comparison to Hofstede’s research, both Inglehart and Schwartz's studies cover a relatively small number of national cultural value dimensions. Therefore, Hofstede’s theory is still by far the most comprehensive national cultural framework in cross-cultural studies.

\section{Qualitative Comparative Analysis}

Social and behavioral researchers often find themselves engaging in qualitative comparative studies examining and comparing cases. Most of the time, these cases are very limited in number for meaningful macro-level comparisons; for example, there are only six states and five political parties in Australia. These numbers are far less than sufficient for undergoing most conventional quantitative statistical analysis. In addition, the main limitation of single case 
studies or multiple case studies is that it is very difficult to produce any form of statistical generalization to a broader population because the findings are only limited to a single or a few cases (Bryman \& Bell, 2007).

American political sociologist, Charles C. Ragin, takes a middle path between quantitative and qualitative methods and develops a new data analysis method called Qualitative Comparative Analysis (QCA) initially for the purpose of solving problems of generalizing the findings of small number of cases at the macro level (Ragin, 1987). Ragin states in his new book, Configurational Comparative Methods, that his ambition is using this method is to "allow systematic cross-case comparisons, while at the same time giving justice to within-case complexity, particularly in small- and intermediate-N research designs” (Rihoux \& Ragin, 2009, p. Xviii).

With the work of Ragin and many other scholars over the past two decades, QCA and its related techniques, including crisp sets (csQCA), multi-value QCA (mvQCA), fuzzy-set (fsQCA), and MSDO/MDSO (most similar, different outcome/ most different, same outcome), were developed and have been productively applied not only in small- and intermediate-N research designs at macro-level, but also in large-N researches at meso- or even micro-level (Rihoux \& Ragin, 2009).

\section{The Importance/Advantage of QCA}

Often for social and behavioral researchers, QCA is more important than quantitative analysis for the reason that almost all social science theory is verbal in natural and also fundamentally formulated in terms of sets and set relations (Ragin, 2008). However, conventional quantitative analysis methods treat independent variables as separable causes of an outcome to explain variation of dependent variables individually. 
Unlike conventional quantitative analysis, QCA places more emphasis on analyzing asymmetric set relations rather than calculating the net effects of independent variables in linear models from a symmetric (correlation and multiple regression) perspective. "In set-theoretic work, the idea of a causal recipe is straightforward, for the notion of combined causes is directly captured by the principle of set intersection” (Ragin, 2008, p. 9). QCA allows researchers to identify the commonalities across a set of observed cases by examining different configurations (combinations) of causally relevant condition variables linked to a particular outcome. In other words, QCA helps researchers to find patterns in the condition variables for the cases they study and make sense of them.

Similar to quantitative analysis approaches, replicability and transparency are the two major advantages QCA has over other qualitative approaches. QCA techniques are formalized techniques due to the reason that they were developed based on set theory and Boolean algebra with fixed and stable rules of logic. In addition, QCA techniques require researchers to act with transparency along the stages of the research process, so that other researchers can easily replicate their studies for confirmation or falsification (Rihoux \& Ragin, 2009).

\section{Fuzzy-set QCA}

Ragin (2000) adopts Zadeh’s fuzzy-set theory to develop fsQCA. This technique allows researchers to calibrate partial membership in sets using values ranging from 0.0 and 1.0 with three-value, four-value, or six-value fuzzy sets or even a continuous fuzzy set (Ragin, 2008; Rihoux \& Ragin, 2009).

Similar to the assessments of significance and strength in analyzing correlational connections, consistency and coverage are the two descriptive measurements used to assess fuzzy set relations. Consistency means determining if a configuration of conditions is necessary 
for an outcome to occur by assessing the degree to which one set is contained within another. Consistency scores have to be .75 or higher to be substantial. Only after a consistent subset of the outcome is established, then it is reasonable to calculate the coverage scores. Coverage means assessing the empirical relevance of a consistent subset (Ragin, 2008; Rihoux \& Ragin, 2009).

If the membership scores in a combination of conditions are consistently less than or equal to the membership scores in the outcome across the cases, then the combination of conditions is a subset of the outcome. Usually, the same outcome may result from different combinations of conditions. Then these combinations are assessed by their coverage of the outcome. A combination that covers a greater proportion of the outcome is more empirically important than a combination that covers a lesser proportion of the outcome.

\section{METHOD}

Individual national cultures consist of complex statements of cultural dimensions representing unique configurations of conditional multiple-value paths to outcomes.

Configurational thinking in terms of degree of membership in different combinations of causally relevant thinking provides unique and useful understanding that goes beyond net-effects approaches (i.e., multiple regression and ANOVA methods) for explaining behavior (Ragin, 2008).

Based upon the literature review and available secondary data, the study proposes a theory that culture has influences on tourist behavior and these influences differ by some consumption moderating variables, including purposes of the trip and prior trip experiences, as well as some sub-cultural dimensions, such as age. At the same time, the study compares 
culture's influences with the influences of demographic figures, such as GDP per capita and home-destination distance. Figure 1 shows the conceptual framework of the study.

Figure 1 here.

The study plans to do a critical test on the four alternative culture value models as well as the demographic figures by using meta-analysis. Meta-analysis is defined as "the statistical analysis of a large collection of analysis results from individual studies for the purpose of integrating the findings (Glass, 1976, p. 3).” Scholars often use meta-analysis for conducting systematic reviews to point out what is already known and what need to be addressed in specific fields (Dickersin \& Berlin, 1922).

The study transforms the country scores of the different cultural values and the behavioral data on consumption into fuzzy-set scores for analysis to find out the impact of the cultural value configurations on consumer behaviors as well as the behavioral tendencies of the consumers in each country. Four sets of the cultural value data and two sets of the secondary consumption data along with the demographic data examined in the study are summarized as follows.

\section{Australian Data}

Prior research by Woodside and Ahn (2008) is the source of the first data set. The Cooperative Research Centre for Sustainable Tourism in Australia funded their research to support the data acquisition from the Australian Bureau of Tourism Research. The data set contains information of 2,630 international visitors to Australia in 2000 from 14 countries, including Canada, Germany, Hong Kong, Indonesia, Japan, Malaysia, Netherlands, New Zealand, 
Singapore, Korea, Switzerland, Taiwan, United Kingdom, and the United States. The respondents are classified into different segments by the three age groups of young $(<30)$, middle (30 49), and old (50+), and the four purposes of their trips, including first-time holiday, firsttime visiting friends and relatives (VFR), repeat holiday, and repeat VFR. The consumption data used in the study to analyze the behavioral tendencies of visitors of different country origin includes average nights of stay, daily trip expenditures, shopping expenditures, and number of the regions and states visited.

Due to the availability of the country scores in the four value data sets, the present study includes analyses of date from ten countries including Germany, Hong Kong, Japan, Malaysia, Netherlands, New Zealand, Singapore, Switzerland, Taiwan, and U.S.A.

\section{American Data}

The second set of the data is published by the Office of Travel and Tourism Industries, International Trade Administration of the U.S. Department of Commerce. The data set includes the inbound travelers to the United States in 2008 from 18 countries; however, due to the availability of the country scores in the four cultural value data sets, only the data of 12 countries, including Australia, Brazil, France, Germany, Italy, Japan, Netherlands, New Zealand, Singapore, Spain, Switzerland, and Taiwan, are analyzed in the study. The consumption data used to analyze the behavioral tendencies of tourists from each country in the study includes average travel spending, length of stay, time spends on planning the trip, and number of the states visited.

\section{Distance \& GDP per Capita Data}

The study retrieves information about flight distance between the main exit airport of each country to Australia and USA from http://www.travelmath.com/distance/. Sydney is the main entrance airport in Australia to receive international arrivals. Los Angeles and New York are the 
main entrance airports on the west and east coast of USA to receive international arrivals (please see Tables $2 \& 3$ for details). The study uses the shorter distance from the main exit airport of each country to either Los Angeles or to New York in the analysis.

Table 2 and 3 here.

Gross domestic product (GDP) per capita is one of the important indexes to represent the economic performance of a country. The study adopts the GDP per capita data from the database of International Monetary Fund (http://www.imf.org/external/data.htm). 2000 GDP per capita is used with the Australian data set and 2008 GDP per capita is used with American data set.

Table 4 \& 5 here.

\section{Key Propositions and Empirical Paradox}

Based on the literature review, the six key propositions and empirical paradox are developed and stated as follows.

\section{P1: Culture is a configuration of values}

Prior studies examine only the influences of individual cultural values on consumer behavior one at a time. In fact, they only study the values, not culture. Since the nature of culture includes various value combinations, cultures' impact need to be examined as configurations of values. The configuration of cultural values should work better in predicting and explaining consumer behavior than the individual values. 


\section{P2: Nations differ in meaningful ways by the configurations of values}

Since the debate on national culture has been going on for a long time, it is necessary to study whether or not culture differs from county to country. National cultures can be described by different configurations of cultural values. For example, Americans are low in power distance, high in individualism, high in masculinity, and low in uncertainty avoidance while Japanese are high in power distance, low in individualism, high in masculinity, and high in uncertainty avoidance by using Hofstede’s national cultural values.

\section{P3: Schwartz $>$ Steenkamp $>$ Hofstede $>$ Inglehart and Baker $>$ GDP \& Distance}

Before doing any analysis, the study predicts that the demographic conditions of GDP per capita and home-destination distance will not work as well as all the four cultural theories. The cultural value theory proposed by Inglehart and Baker may be the least effective in explaining tourist behavior amongst the four cultural theories because it only covers two cultural values while the other theories include four or more cultural values. Schwartz's theory may work better than all the other theories because it is based on a sounded priori theory, and has not received any critiques yet. On the other hand, Hofstede's theory is conducted 30 years ago and has been attacked by many scholars. Steenkamp’s theory should be placed in between Schwartz's and Hofstede's theories because it is based on the two theories. However, each of the theories has its own strengths and weaknesses in explaining consumer behaviors.

\section{P4: Cultural influences differ by purposes of the trip and previous trip experience}

The degree of cultural influences is greater for people travel for holiday purposes than for people traveling to visit friends and relatives. For the latter, their friends and relatives are very likely to open their homes to them and make arrangements for their trips. Thus, the influences of their friends and relatives on the consumption behavior are greater than culture. 
The degree of cultural influences is greater for first-time visitors than those who have previous experiences. For those who have previous experiences, the influences, such as demographic figures and previous trip experiences, are greater than culture.

\section{P5: Culture affects consumer behavior}

Culture affects consumer behavior in different ways. There are different consumption patterns between eastern and western cultures. For example, (1) People from western cultural countries tend to stay longer on a trip to a foreign country than people from eastern cultural countries, because eastern cultures are high in power distance and hierarchy. Thus, people from eastern cultural countries need to return their homes to maintain their positions after a short trip.

(2) People from eastern countries may spend more on their trip everyday than people from western countries, because eastern cultures are high in uncertainty avoidance and masculinity. Not only they do not want to worry about food or accommodation in a foreign country, but also they want to show that they are able to stay in a five-star hotel and have some fancy meals.

(3) People from eastern cultural countries are more likely to spend more money on shopping than people from western cultural countries, because western cultures are high in individualism and eastern cultures are high in collectivism. People from eastern cultural countries are more likely to buy more gifts for their relatives and friends at home than people from western cultural countries. Thus, people from eastern cultural countries are more likely to shop for their friends and family at home.

(4) People from western cultural countries are more likely to visit more places than people from eastern cultural countries, because western cultures are high in individualism. (5) Although eastern cultures are high in uncertainty avoidance, people from eastern cultural countries do not 
spend as much time as people from western cultural countries on their pre-trip planning. That is because people from eastern cultural countries tend to join group tours and take short trips.

\section{P6: Cultural influences differ by age}

Many people think that culture is becoming less important for young people than for old people because of their conceptions that old people are more cultured and traditional, but young people are less traditional and even repelled by traditions. However, scholars, such as Hofstede (2001, 2002) and Schwartz (2006), believe that culture has "centuries-old roots" and it changes very slowly. Therefore, the findings of the proposition testing will either support or refute the belief that the degree of cultural influences differs by age.

\section{ANALYSIS AND FINDINGS}

In order to test the propositions the study first evaluated the consistency and coverage scores of the fuzzy set relations of individual cultural values as well as cultural value configurations on different outcome conditions from the Australian and American data sets based on the four alternative cultural value theories to determine whether the individual values or the combination of the cultural values would work better in predicting tourists' consumption behaviors.

Second, the study identifies the best cultural value configuration in each of the four cultural value theories to represent each country by choosing the maximum score from the various cultural value configuration scores.

Third, the study adopts a restricted meta-analysis to analyze only the consistency scores over 0.749 of the best fitting models in each of the four theories as well as the demographic conditions to conclude with the most useful theory in explaining and predicting consumer 
behavior. "Restricted meta-analysis" includes estimating the number of substantial consistency scores and their ranges for findings testing a given theory.

Fourth, restricted meta-analysis allows the study to explore whether or not the degree of cultural influences on consumer behavior changes by the first-time travelers and repeat travelers as well as their trip purposes of spending the holiday only or visiting friends and relatives.

Fifth, the study adopts the best cultural theory to find out the consumption patterns of tourists from different countries as well as compare the consumption patterns of people from eastern countries and western countries, and then verify if the consumption patterns of tourists from different countries are consistent in both of the Australian and the American data sets.

Finally, restricted meta-analysis allows the study to explore whether the degree of cultural influences on consumer behavior differs by the three different age groups of young, middle, and old.

\section{Calibrating variables into fuzzy membership scores}

In order to transform the original cultural variables and behavioral variables into fuzzy membership scores, it is necessary to calibrate them by identifying the thresholds for full membership (fuzzy score=0.95), cross-over point (fuzzy score=0.50), and full non-membership (fuzzy score $=0.05$ ). Please see the following two tables for details.

Table 6 and 7 here.

\section{P1: Culture is a configuration of values}

Fuzzy set membership scores of cultural values from the four cultural theories and consumption data from Australian and American data sets are input into fsQCA software 
program for analysis. Note that for Australian data sets, only the data of first-time holiday visitors to Australia are used to demonstrate the analysis.

In order to estimate whether individual cultural values or the configurations of cultural values work better in predicting and explaining the behavioral outcomes, consistency and coverage scores are evaluated. According to Ragin (2000, 2008), consistency scores should be equal to or higher than coverage scores to indicate the antecedent conditions are subsets of the outcome conditions. In addition, consistency scores should be at least 0.75 or higher to indicate that the antecedent conditions are sufficient for the outcome conditions to occur.

Table 8 lists the best predicting individual values and the best predicting configuration of values for the outcome condition by using the data from Hofstede's country scores and first-time holiday visitors to Australia. Table 8 shows that all the best configurations of Hofstede’s cultural values have higher consistency scores than all the best individual cultural values. Tables 9, 10, and 11 show similar results by using Inglehart, Schwartz, and Steenkamp’s data. As Tables 8, 9, 10, and 11 show, the average improvement possible of the consistency scores of fuzzy set relations are 29.09\%, 40.09\%, 77.44\%, and 40.32\% for Hofstede, Inglehart, Schwartz, and Steenkamp, respectively.

Tables 8-11 here.

Similar to the analysis with Australian consumption data, the analysis with American consumption data also shows the configurations of cultural values score higher in consistency than individual values for Hofstede, Inglehart, Schwartz, and Steenkamp's theories (see Tables 12 15 for details). The average improvement possible of the consistency scores of fuzzy set 
relations are 58.58\%, 54.96\%, 46.26\%, and 68.14\% for Hofstede, Inglehart, Schwartz, and Steenkamp respectively. Thus, based on the analysis above, cultures are viewable usefully as configurations of values, instead of individual values, when studying culture's influences on consumer behavior.

Tables 12-15 here.

\section{P2: Nations differ in meaningful ways by configurations of values}

In order to find out the best cultural configuration to represent each country with each of the four cultural theories, cultural value scores of each country from Hofstede, Inglehart, Schwartz, and Steenkamp’s theories are input into EXCEL for analysis. A country’s representative cultural configuration is identified by choosing the maximum score from all the possible cultural configuration scores of that country.

The study examines data from 15 countries including Australia, Brazil, France, Germany, Hong Kong, Italy, Japan, Malaysia, Netherlands, New Zealand, Singapore, Spain, Switzerland, Taiwan, and USA, are studied. Tables 16, 17, 18, and 19 show the representative cultural configurations for each country by using Hofstede, Inglehart, Schwartz, and Steenkamp’s cultural theories, respectively.

Table 16 here.

Although there are 16 possible cultural configurations with four cultural values of Hofstede's theory, not all of them exist in the countries studied in the paper. Table 16 shows that 
all the eastern countries, including Hong Kong, Japan, Malaysia, Singapore, and Taiwan, in the study are high in power distance and low in individualism while most western countries are low in power distance, except for Italy, France and Spain, and high in individualism, except for Italy. Unlike other western countries, Italy and Netherlands are special and their cultural configurations are exactly opposite to each other.

Table 17 here.

Only four possible cultural configurations exist with Inglehart's theory because he only comes up with two cultural value dimensions. As Table 17 shows, Singapore is culturally distinct from all the other 14 countries in the study and Singapore is high in both traditional and survival dimension. Other Asia countries, such as Hong Kong, Japan, and Taiwan are low in traditional (high in secular-rational) and high in survival values. European countries, including France, Germany, Italy, Netherlands, Spain, and Switzerland, are grouped together with Australia and New Zealand as high secular and high self-expression countries. However, since New Zealand is located in the boundary between traditional and secular-rational values, New Zealand can also be grouped with Brazil, Malaysia and USA as high traditional and high self-expression country.

Table 18 here.

Schwartz’s seven cultural values permit 128 possible cultural configurations. More cultural configurations are useful to represent the 15 countries in the study comparing to the other three cultural theories. Most eastern countries, except for Japan, are low in affective autonomy and 
high in embeddedness while most western countries are high in affective autonomy and low in embeddedness.

Table 19 here.

With Steenkamp’s theory, most western countries are high in autonomy, except for Italy, and high in egalitarianism, except for Australian, New Zealand, and USA, while most eastern countries are low in both autonomy and egalitarianism, except for Japan, which is high in autonomy.

Besides Inglehart's theory with the limitation of including more than four cultural configurations due to the only two cultural value dimensions it has, Hofstede, Schwartz, and Steenkamp's theories show that distinct cultural differences exist between eastern and western countries no matter which one of the three culture theories applies. Eastern countries, such as Hong Kong, Japan, Malaysia, Singapore, and Taiwan, either stand out alone with unique cultural configurations or group together with other Eastern countries. Same applies to the western countries. Among the 15 countries in the study, the cultural configuration of Brazil is the same as that of some eastern and western countries. For example, Brazil's cultural configuration is not only the same as Taiwan's with Hofstede, Schwartz, and Steenkamp's theories, but also the same as New Zealand and USA's with Inglehart's theory.

The study illustrates how culture affects consumer behaviors by showing the consumption patterns of some countries in the fifth proposition testing. 


\section{P3: Schwartz $>$ Steenkamp $>$ Hofstede $>$ Inglehart $>$ GDP \& Distance}

Meta-analysis is used to estimate the usefulness of the four cultural theories and demographic conditions (GDP per capita and home-destination distance) in explaining and predicting consumer behavior. Consistency scores over 0.749 of the best fitting models of the four theories and G·D on affirmation and negation of the four consumption data, including length of stay, not length of stay, daily expenditure, not daily expenditure, shopping expenditure, not shopping expenditure, number of states/regions visited, and not number of states/regions visited for international inbound visitors to Australia. Same analysis applies to the American consumption data, including length of stay, not length of stay, pre-trip planning, not pre-trip planning, shopping expenditure, not shopping expenditure, number of states/regions visited, and not number of states/regions visited for international inbound visitors to USA.

Figure 2 shows that after analyzing Australian consumption data, Schwartz's theory is the most useful one followed by Steenkamp’s, Inglehart's, G·D, and Hofstede’s theory in explaining and predicting consumer behavior. Not only is the mean consistency score of Schwartz's theory higher than those of the other three theories and the demographic figures, but also the range of the means plus and minus 1.96 standard errors of Schwartz's theory is tighter than those of the others. In other words, the findings of the meta-analysis indicate that Schwartz's theory is more powerful and can more accurately estimate consumer behavior than the other three theories as well as the demographic figures.

However, the analysis on the American consumption data shows different findings. Figure 3 shows Hofstede, Inglehart, and Schwartz’s theories are perform better than Steenkamp’s theory and the demographic figures in explaining and predicting consumer behaviors. Also, the ranges of the theories in Figure 3 are much wider than those in Figure 2. The disagreement of the 
findings of the two analyses may mainly result from the numbers of the consistency score in the Australian data analysis are more than those in the American data analysis.

Figure 2 and 3 here.

\section{P4: Cultural influences differ by purposes of the trip and previous trip experience}

Meta-analysis applies to analyze whether cultural influences on consumer behavior differ by purposes of the trip and previous experience. Figures 4 to 8 show the findings of metaanalysis by four purposes of the trip for visitors to Australia with Hofstede, Inglehart, Schwartz, and Steenkamp’s theories as well as the demographic figures.

As Figures 4 to 7 show, the ranges of the means plus and minus 1.96 standard errors of first-time holiday purpose for all the four cultural theories are obviously narrower than those of the other three purposes for all the four cultural theories. That means cultural configurations are able to estimate the behaviors more accurately for first-time holiday visitors than visitors with other trip purposes and previous experience. In other words, culture's influences are stronger for first-time holiday visitors than VFR visitors and repeat visitors.

On the contrary, Figure 8 shows the ranges of the means plus and minus 1.96 standard errors of repeat VFR purpose for the demographic figures is much tighter than those of the other three purposes. This indicates the configuration of GDP per capita and home-destination distance can estimate consumer behavior more precisely for repeat VFR visitors than visitors with other trip purposes. In other words, demographic figures have stronger influence for repeat VFR visitors than visitors on holiday purpose and without previous experience. 
In addition, Figures 4 to 7 also show that Schwartz's theory is more theoretically and empirically reasonable compared to the other three theories. This can be explained by the patterns of the four trip purposes in the findings of meta-analysis as shown in Figure 11 that not only the mean consistency scores from high to low, but also the ranges of the means plus and minus 1.96 standard errors from narrow to wide are in the order of first-time holiday, repeat holiday, first-time VFR, and repeat VFR. The findings comply with the theory that cultural influences are stronger for holiday visitors than VFR visitors as well as for first-time visitors than repeat visitors.

Therefore, the findings of the meta-analysis shown in these five figures confirm the research proposition that culture has powerful influences on the behaviors of first-time holiday visitors. On the other hand, for those who either have experiences in a foreign country or travel on VFR purpose, other influences become stronger, such as GDP per capita and homedestination distance, than cultural influence. The findings also re-affirm the third proposition that Schwartz's theory is more theoretically and empirically useful in explaining and predicting consumer behavior than the other theories.

Figures 4-8 here.

\section{P5: Culture affects consumer behavior}

The study conducts the proposition testing in three parts to explore whether culture affects consumer behavior and whether the differences of consumption behavior exist between eastern and western cultures. First, the study identifies the consumption patterns of the countries with their representative cultural configurations. Second, the study compares the findings of 
Australian and American consumption data sets to see if the consumption behavioral patterns are consistent in both data sets. Third, the study uses the best fitting models for the consumption behaviors to illustrate how people from eastern countries behave differently from people from western countries.

Due to the consistency of the findings relevant to the third proposition, Schwartz's cultural theory is the most useful theory in explaining consumer behavior in the context in the study — the study uses only Schwartz’s cultural value configurations to analyze the consumption data.

The findings of the fourth proposition testing suggests cultural influences are stronger for first-time holiday visitors than visitors travel on other purposes, so the study uses only the data of first-time holiday visitors in Australian consumption data set. In addition, the findings of the second proposition testing show that Japan and Netherlands are the most special eastern and western countries among the countries in the study, thus the study uses Schwartz's cultural value configurations for Japan and Netherlands to illustrate the influences of culture on consumer behavior for the first two parts of the proposition testing in this section.

Figure 9 shows Japanese cultural configuration works well in explaining consumer behavior for first-time holiday visitors to Australia by using Schwartz’s cultural theory. Japanese cultural configuration explains and predicts that visitors with strong Japanese cultural characteristics tend to not stay long, spend much money on food and accommodations daily, buy a lot gifts to bring home, and visit a few regions during their trips to Australia. On the contrary, Figure 10 shows that Netherland's cultural configuration explains visitors with strong Dutch cultural characteristics tend to stay long, spend little money on food and accommodations daily, not buy many gifts to bring home, and visit many places during their trips to Australia. 
The study includes American consumption data to see if the consumption behaviors of Japan and Netherland's cultural configurations are consistent for international visitors travel to Australia and USA. Both Figures 11 and 12 show similar findings to figures 9 and 10. Figure 11 shows visitors with strong Japanese cultural characteristics tend to not stay long, spend much money on shopping, visit a few states during their trips to USA, and spend little time on planning before the trips. Opposite to Japanese cultural configurations, Figure 12 shows that visitors with strong Dutch cultural characteristics are more likely to stay long, visit many states during their trips to USA, and spend much time on planning before the trips.

A disagreement occurs between the findings of Australian and American data sets for the shopping behavior for Netherland's cultural configuration. Visitors with strong Dutch cultural characteristics tend to spend little money on gift shopping when visiting Australia, but they tend to spend much money on shopping when visiting USA. However, Figure 12 shows that Netherlands is the only exception in the shopping XY plot, which means Netherlanders do not spend much money on shopping.

Figures 9-12 here.

Figures 13 and 14 summarize the findings of Schwartz's best fitting models for visitors to Australia and USA, respectively. Figure 13 shows western countries, such as Germany, Netherlands, and Switzerland, usually stand out on the upper right side of the plots for consumption behaviors, including in length of stay, not daily expenditure, not shopping, and number of states visited. This shows that people from western countries are more likely to stay 
more nights, spend less money on food and accommodation daily, shop fewer gifts to bring home, and visit more regions during their trips to Australia than people from eastern countries.

On the contrary, eastern countries, such as Taiwan, Singapore, and Japan, usually appear on the upper right of the plots for consumption behaviors, including not length of stay, daily expenditure, shopping, and not \# of states visited. The findings indicate that people from eastern countries tend to stay fewer nights, spend more money on food and accommodation daily, shop more gifts to bring home, and visit fewer regions during their trips to Australia than people from western countries.

Figure 14 shows similar findings that people from western countries, such as New Zealand, Switzerland, and Netherlands, tend to stay more nights, spend less money on shopping, visit more states during their trips to USA, and spend more time on planning before their trips than people from eastern countries. On the other hand, people from eastern countries, such as Japan, Taiwan, and Singapore, are more likely to stay fewer nights, spend more money on shopping, visit fewer states during their trips to USA, and spend less time on planning before their trips than people from western countries.

Therefore, the findings support the conclusions that culture affects consumer behavior and people from eastern countries do not behave the same as people from western countries.

Figure 13 and 14 here.

\section{P6: Cultural influences differ by age}

Since the findings of the third and the fifth proposition testing suggest Schwartz's theory is theoretically and empirically useful in explaining consumer behavior and the degree of cultural 
influences is greater for visitors who travel to Australia on first-time holiday purpose than other purposes, the study analyzes the consumption data of first-time visitors to Australia with the best fitting models of Schwartz's theory to investigate whether or not the degree of cultural influences change by the three age groups of young $(<30)$, middle (30-49), and old (50+) people.

The findings of a restricted meta-analysis with Schwartz's best fitting models show the mean consistency scores are 0.962, 0.940, and 0.963 for young, middle, and old people, respectively. These three mean consistency scores are all high, which indicates culture strongly influences the consumption behavior about equally for all the three age groups of people. The slight variation of the mean consistency scores among the three different age groups implies cultural influences do not differ by age. The same analysis applies with demographic conditions of GDP per capita and home-destination distance. The findings also suggest demographic figures do influence the consumption behavior for all the three age groups of people, but the influences do not vary by age.

The study examines the consumption behaviors of the three age groups to gain further understandings of cultural influences on different consumption behaviors for the three age groups of people. All the consistency scores of fuzzy set relations are high; these findings indicate cultural influences are strong for all the three age groups of people on different consumption behaviors. Besides that, findings of slight variations of the consistency scores imply the degree of cultural influences do not change by age on different consumption behaviors. (Details are available from anyone of the three authors.) In addition, similar patterns across three different age groups for each of the consumption behaviors also suggest cultural influences are about the same for different age groups of people. Therefore, the findings support the conclusion that cultural influences do not differ substantially by age. 


\section{CONCLUSION, LIMITATIONS, AND MANAGEMENT PRACTICE IMPLICATIONS}

National culture consists of a complex combination of cultural values acting jointly to influence the behavior of the people in a nation. fsQCA allows the study to investigate how complex cultural influences affect consumer behavior. After analyzing the consumption data of international visitors to Australia and USA, the study is able to come to the following conclusions.

First, configurations of cultural values work better than individual values alone in explaining and predicting consumer behavior so that cultural values need to be studied together at the same time, not one at a time. Prior researchers frequently state that they study culture's influences on consumer behavior; however, they only study individual cultural values one at a time. Based on the findings of the first proposition testing, the study suggests future researchers to treat cultural values together as a whole when studying culture's influences on consumer behavior.

Second, the findings show that nations differ in meaningful ways and can be represented by special configurations of cultural values. The study confirms the idea proposed by Clark (1990), Dewar \& Parker (1994), Hofstede (2002), Schwartz (2006), and Steenkamp (2001) that nation is a meaningful proxy for culture because within country commonalities and between country differences do exist. Thus, there is still a need to study culture on national basis.

Third, the findings show that Schwartz's cultural theory is more theoretically and empirically useful compared to Hofstede, Inglehart, and Steenkamp's cultural theories and the demographic figures of GDP per capita and home-destination distance. Hence, the study suggests future researchers adopt Schwartz's theory when studying culture's influences on consumer behavior. 
Fourth, the degree of cultural influences is greater for holiday visitors than VFR visitors as well as for first-time visitors than repeat visitors. Accordingly, researchers should focus more on first-time holiday visitors than visitors traveling for other purposes and repeat visitors, when studying culture’s influences on consumer behavior.

Fifth, the findings support the proposition that culture does have influences on consumer behavior. In addition, obvious divergences exist in the behaviors of people from eastern countries and western countries. Therefore, researchers may conduct further investigations on the influences of culture on consumer behavior when doing cross-cultural studies.

Sixth, the findings show that young, middle-aged, and older people from the same country behave in very similar ways when traveling overseas. In other words, cultural influences do not differ by age. This conclusion supports the belief of Hofstede (2001, 2002) and Schwartz (2006) that culture has centuries-old roots and it changes very slowly. Although people may think culture is becoming less important now than before, it still influences people's behaviors deeply. Therefore, further studies of culture’s influences on consumer behavior are still necessary.

\section{Limitations}

Due to the limitation of time and resources, this study has some notable limitations. First, the cases used in the study are on the national level, instead of the individual level. Although differences exist between individuals, culture is commonly shared by the population of a country. Thus, the study only focuses on the macro level rather than micro level data analysis.

Second, the study only tests four major cultural theories of consumer behavior, even though many other cultural theories are available. Some cultural theories, which have not yet become well-known or applied widely, may work better than the four theories in the study. 
Third, due to the available secondary data, the study only examines five types of consumption behavior; length of stay, daily expenditure, shopping expenditure, number of states/regions visited, and pre-trip planning time.

Fourth, due to the same reason, the study examines only international tourists from fifteen countries. Fifth, both destination countries, Australia and USA, in the study belong to western countries. The question of whether tourists behave differently when visiting eastern countries, such as China and Japan, remains unknown.

According to the limitations of the study, the findings provide several directions for researchers in their future studies. Researchers may adopt other cultural theories and include more countries in their studies to investigate culture's influences on other aspects of consumer behavior of visitors travelling to other destination countries.

\section{Implications for Management Practice}

Based on the findings, the study provides helpful clues for countries' destination management organizations and hospitality firms in designing marketing plans to attract international tourists. Host country may design different tour packages and emphasize different highlights to attract visitors from different countries.

In order to attract people from eastern countries, such as Japan, Singapore, and Taiwan, tourism operators in the host country will likely be effective by designing tour packages of up to 5 to 7 days with 4 or 5-star hotel accommodations and emphasize just a few attractions and quality shopping places in marketing campaigns and frequently broadcast the commercials on $\mathrm{TV}$, radio, or other media during the period of time between one and two months prior to national holidays or summer and winter vacations. 
On the contrary, to attract people from western countries, such as Germany, Netherlands, and Switzerland, management organizations and hospitality firms in the host country will likely be effective by providing many mid-priced range accommodation choices with discounts for staying for a week or longer and information about many tourist attractions and make these information always publicly available in ads, brochures, travel magazines, tourist information websites or any other media for western travelers to make their long trip plans. 


\section{References}

Armstrong, J. S., Brodie, R. J., \& Parsons, A. G. (2001). Hypotheses in marketing science: Literature review and publication audit. Marketing Letters, 12(2), 171-187.

Bryman, A., \& Bell, E. (2007). Business research methods (2 ed.). New York: Oxford University Press Inc.

Carlsmith, J. M., Ellsworth, P. C., \& Aronson, E. (1976). Methods of research in social psychology. Reading, MA:Addison-Wesley.

Clark, R., Ramsbey, T. W., \& Adler, E. S. (1991). Culture, gender, and labor force participation: A cross-national study. Gender and Society, 5(1), 47-66.

Clark, T. (1990). International marketing and national character: A review and proposal for an integrative theory. Journal of Marketing, 54(4), 66-79.

Craig, C. S., \& Douglas, S. P. (2006). Beyond national culture: Implications of cultural dynamics for consumer research. International Marketing Review, 23(3), 322-342.

Dawar, N., \& Parker, P. (1994). Marketing universals: Consumers' use of brand name, price, physical appearance, and retailer reputation as signals of product quality. Journal of Marketing, 58(2), 81-95.

de Mooij, M. (2001). Convergence and divergence in consumer behavior: Consequences for global marketing and advertising. (doctoral dissertation). University of Navarra, Pamplona, Spain.

Dickersin, K., \& Berlin, J. A. (1992). Meta-analysis: State-of-the-science. Epidemiologic Reviews, 14, 154-176. 
Douglas, S. P., \& Craig, C. S. (1997). The changing dynamic of consumer behavior: Implications for cross-cultural research. International Journal of Research in Marketing, 14(4), 379-395.

Douglas, S. P., \& Craig, C. S. (2006). On improving the conceptual foundations of international marketing research. Journal of International Marketing, 14(1), 1-22.

Fernandez, D. R., Carlson, D. S., Stepina, L. P., \& Nicholson, J. D. (1997). Hofstede's country classification 25 years later. Journal of Social Psychology, 137(1), 43-54.

Glass, G. V. (1976). Primary, secondary, and meta-analysis of research. Educational Researcher, 5(10), 3-8.

Harrison, G. L. (1993). Reliance on accounting performance measures in superior evaluative style- The influence of national culture and personality. Accounting, Organization and Society, 18(4), 319-339.

Hofstede, G. (1980). Culture's consequences: International differences in work-related values. Beverly Hills, California: Sage Publications.

Hofstede, G. (1983). National cultures in four dimensions: A research-based theory of cultural differences among nations. International Studies of Management and Organization, 13(1/2), 46-74.

Hofstede, G. (2001). Culture's consequences: Comparing values, behaviors, institutions, and organizations across nations. (2nd ed.). Thousand Oaks, CA: Sage Publications, Inc.

Hofstede, G. (2002). Dimensions do not exist: A reply to Brendan McSweeney. Human Relations, 55(11), 1355-1361.

Hoppe, M. H. (1990). A comparative study of country elites: International differences in workrelated values and learning and their implications for international management training 
and development (Doctoral Dissertation). University of North Carolina at Chapel Hill, Chapel Hill, CA.

Inglehart, R., \& Baker, W. E. (2000). Modernization, cultural change, and the persistence of traditional values. American Sociological Review, 65(1), 19-51.

Inglehart, R., \& Norris, P. (2003). Rising Tide: Gender Equality and Cultural Change around the World. New York: Cambridge University Press.

Inglehart, R., \& Welzel, C. (2005). Modernization, cultural change, and democracy: the human development sequence. New York: Cambridge University Press.

Lazarsfeld, P. F. (1937). Some remarks on typological procedures in social research. Zeitscchrift fur Sozialforschung, 6, 119-139.

Litvin, S. W., Crotts, J. C., \& Hefner, F. L. (2004). Cross-cultural tourist behaviour: A replication and extension involving Hofstede's uncertainty avoidance dimension. The International Journal of Tourism Research, 6(1), 29-37.

Lynn, M., Zinkhan, G. M., \& Harris, J. (1993). Consumer tipping: A cross-country study. Journal of Consumer Research, 20(3), 478-488.

McSweeney, B. (2002). Hofstede's model of national cultural differences and their consequences: A triumph of faith - A failure of analysis. Human Relations, 55(1), 89-118.

Merritt, A. (2000). Culture in the cockpit: Do Hofstede's dimensions replicate? Journal of CrossCultural Psychology, 31(3), 283-301.

Mouritzen, P. E., \& Svara, J. H. (2002). Leadership at the apex: Politicians and administrators in western local governments. Pittsburgh, PA: University of Pittsburgh Press.

Nakata, C., \& Sivakumar, K. (1996). National culture and new product development: An integrative review. Journal of Marketing, 60(1), 61-72. 
Ng, S. I., Lee, J. A., \& Soutar, G. N. (2007). Tourists' intention to visit a country: The impact of cultural distance. Tourism Management, 28(6), 1497-1506.

Ragin, C. C. (1987). The comparative method. Moving beyond qualitative and quantitative strategies. Berkeley, CA: University of California Press.

Ragin, C. C. (2000). Fuzzy-set social science. Chicago, IL: University of Chicago Press.

Ragin, C. C. (2008). Redesigning social inquiry: Fuzzy sets and beyond. Chicago, IL: The University of Chicago Press.

Rihoux, B., \& Ragin, C. C. (2009). Configurational comparative methods: Qualitative comparative analysis (QCA) and related techniques. Thousand Oaks, CA: Sage.

Schwartz, S. H. (1994). Beyond individualism/collectivism: New cultural dimensions of values. In U. Kim, H. C. Triandis, C. Kagitcibasi, S.-C. Choi \& G. Yoon (Eds.), Individualism and Collectivism: Theory, Method and Applications (pp. 85-119). California: Sage Publications.

Schwartz, S. H. (2006). A theory of cultural value orientations: Explication and applications. Comparative Sociology, 5(2-3), 137-182.

Shane, S. (1994). The effect of national culture on the choice between licensing and direct foreign-investment. Strategic Management Journal, 15(8), 627-642.

Sivakumar, K., \& Nakata, C. (2001). The stampede toward Hofstede's framework: Avoiding the sample design pit in cross-cultural research. Journal of International Business Studies, 32(3), 555-574.

Soares, A. M., Farhangmehr, M., \& Shoham, A. (2007). Hofstede's dimensions of culture in international marketing studies. Journal of Business Research, 60, 277-284. 
Steenkamp, J.-B. E. M. (2001). The role of national culture in international marketing research. International Marketing Review, 18(1), 30-44.

Taras, V. (2010). Catalogue of Instruments for Measuring Culture. Retrieved March 26, 2010, from http://vtaras.com/Culture_Survey_Catalogue

Triandis, H. C. (1989). The self and social behavior in differing cultural contexts. Psychological Review, 96(3), 506-520.

van Nimwegen, T. (2002). Global banking, global values: The in-house reception of the corporate values of ABN AMRO. Nyenrode University, Delft, The Netherlands.

Veiga, J. F., \& Floyd, S. (2001). Towards modelling the effects of national culture on IT implementation and acceptance. Journal of Information Technology, 16(3), 145-158.

Woodside, A. G., \& Ahn, I. (2008). Cultures' consequences on experiencing international tourism services and products. In A. G. Woodside \& D. R. Martin (Eds.), Tourism Management. London, England: CABI.

World_Tourism_Organization. (2001). Tourism 2020 Vision. Retrieved February 5, 2010, from http://unwto.org/facts/menu.html

World_Tourism_Organization. (2009). UNWTO World Tourism Barometer. Retrieved from http://unwto.org/facts/eng/pdf/barometer/UNWTO_Barom09_1_en.pdf 
Table 1: Comparison of Major Cultural Theories and Dimensions

\begin{tabular}{|l|c|c|c|c|}
\hline & Hofstede (1980) & $\begin{array}{c}\text { Inglehart \& } \\
\text { Baker (2000) }\end{array}$ & $\begin{array}{c}\text { Schwartz } \\
(1994,2006)\end{array}$ & $\begin{array}{c}\text { Steenkamp } \\
(2001)\end{array}$ \\
\hline Authority & Power Distance & $\begin{array}{c}\text { Traditional vs. } \\
\text { Secular-rational }\end{array}$ & $\begin{array}{c}\text { Egalitarianism } \\
\text { vs. Hierarchy }\end{array}$ & $\begin{array}{c}\text { Egalitarianism } \\
\text { vs. Hierarchy }\end{array}$ \\
\hline Self \& Group & $\begin{array}{c}\text { Individualism } \\
\text { vs. Collectivism }\end{array}$ & $\begin{array}{c}\text { Survival vs. } \\
\text { Self-expression }\end{array}$ & $\begin{array}{c}\text { Autonomy vs. } \\
\text { Embeddedness }\end{array}$ & $\begin{array}{c}\text { Autonomy vs. } \\
\text { Collectivism }\end{array}$ \\
\hline $\begin{array}{l}\text { Social/ natural } \\
\text { environment }\end{array}$ & $\begin{array}{c}\text { Masculinity vs. } \\
\text { Femininity }\end{array}$ & & $\begin{array}{c}\text { Mastery vs. } \\
\text { Harmony }\end{array}$ & $\begin{array}{c}\text { Mastery vs. } \\
\text { Nurturance }\end{array}$ \\
\hline Uncertainty & $\begin{array}{c}\text { Uncertainty } \\
\text { Avoidance }\end{array}$ & & & $\begin{array}{c}\text { Uncertainty } \\
\text { Avoidance }\end{array}$ \\
\hline
\end{tabular}

Table 2: Distance between the Main Exit Airport of Each Country and Sydney, Australia

\begin{tabular}{ccc} 
Country & Airport & To Sydney (Miles) \\
\hline Germany & Frankfurt & 10,240 \\
Hong Kong & Hong Kong & 4,566 \\
Japan & Tokyo & 4,842 \\
Malaysia & Kuala Lumpur & 4,108 \\
Netherlands & Amsterdam & 10,339 \\
New Zealand & Auckland & 1,342 \\
Singapore & Singapore & 3,918 \\
Switzerland & Zurich & 10,294 \\
Taiwan & Taipei & 4,498 \\
USA & Los Angeles & 7,496
\end{tabular}

Table 3: Distance between the Main Exit Airport of Each Country and USA

\begin{tabular}{cccc} 
Country & Airport & $\begin{array}{c}\text { To Los Angeles } \\
\text { (Miles) }\end{array}$ & $\begin{array}{c}\text { To New York } \\
\text { (Miles) }\end{array}$ \\
\hline Australia & Sydney & 7,496 & 9,934 \\
Brazil & Rio de Janeiro & 6,293 & 4,803 \\
France & Paris & 5,658 & 3,636 \\
Germany & Frankfurt & 5,794 & 3,864 \\
Italy & Rome & 6,345 & 4,292 \\
Japan & Tokyo & 5,487 & 6,755 \\
Netherlands & Amsterdam & 5,569 & 3,654 \\
New Zealand & Auckland & 6,511 & 8,815 \\
Singapore & Singapore & 8,782 & 9,531 \\
Spain & Madrid & 5,832 & 3,595 \\
Switzerland & Zurich & 5,932 & 3,941 \\
Taiwan & Taipei & 6,790 & 7,799
\end{tabular}


Table 4: 2000 GDP per Capita of Each Country

$\begin{array}{cc}\text { Country } & \text { 2000 GDP Per Capita } \\ \text { (US dollars) }\end{array}$

Table 5: 2008 GDP per Capita of Each Country

$\begin{array}{cc}\text { Country } & \text { 2008 GDP Per Capita } \\ \text { (US dollars) }\end{array}$


Table 6: Calibrating cultural variables into fuzzy membership scores

\begin{tabular}{c|lccc} 
& Cultural values & 0.95 & 0.50 & 0.05 \\
\hline \multirow{5}{*}{ Hofstede } & Power distance & 80 & 50 & 20 \\
& Individualism/collectivism & 80 & 50 & 20 \\
& Masculinity/femininity & 80 & 50 & 20 \\
& Uncertainty avoidance & 80 & 50 & 20 \\
\hline \multirow{2}{*}{ Inglehart } & Traditional/secular-rational & -1.5 & 0 & 1.5 \\
& Survival/self-expression & -1.5 & 0 & 1.5 \\
\hline \multirow{5}{*}{ Schwartz } & Affective autonomy & 4.1 & 3.6 & 3.1 \\
& Intellectual autonomy & 5.1 & 4.3 & 3.75 \\
& Embeddedness & 4.4 & 3.9 & 3.35 \\
& Hierarchy & 2.75 & 2.5 & 2.3 \\
& Mastery & 4.3 & 4.16 & 4.0 \\
& Egalitarianism & 5.33 & 5.1 & 4.7 \\
& Harmony & 4.1 & 3.7 & 3.38 \\
\hline \multirow{5}{*}{ Steenkamp } & Egalitarianism/hierarchy & 90 & 0 & -90 \\
& Autonomy/collectivism & 90 & 17.5 & -55 \\
& Mastery/nurturance & 80 & 15 & -50 \\
& Uncertainty avoidance & 60 & -7.5 & -75
\end{tabular}

Table 7: Calibrating behavioral variables into fuzzy membership scores

\begin{tabular}{c|l|ccc}
\multicolumn{2}{c|}{ Behavioral variables } & 0.95 & 0.50 & 0.05 \\
\hline \multirow{3}{*}{$\begin{array}{c}\text { Australian } \\
\text { Data Sets }\end{array}$} & Nights & 30 & 14 & 5 \\
& Daily expenditure & 350 & 180 & 50 \\
& Shopping & 1000 & 500 & 300 \\
& States/regions visited & 10 & 3 & 1 \\
\hline \multirow{3}{*}{ American } & Nights of stay & 12 & 8 & 4 \\
Data Sets & Travel spending & 4000 & 3000 & 2000 \\
\multicolumn{2}{c}{ States visited } & 2 & 1.5 & 1 \\
\multicolumn{2}{c}{ Distance to Sydney } & 90 & 60 & 1500 \\
\multicolumn{2}{c}{ Per Capitance to US } & 10000 & 5000 & 3500 \\
\multicolumn{2}{c}{ Per Capita GDP 2008 } & 8700 & 6100 & 4000 \\
& Pre-trip planning days & 36000 & 20000 & 8000
\end{tabular}


Table 8: Consistency and coverage scores of the causal fuzzy set relations of the best Hofstede's individual and the configuration of cultural values on the Australian outcome conditions

\begin{tabular}{|c|c|c|c|}
\hline $\begin{array}{c}\text { Outcome } \\
\text { Condition }\end{array}$ & $=\mathrm{f}(\mathrm{P}) ;=\mathrm{f}(\mathrm{I}) ;=\mathrm{f}(\mathrm{M}) ;=\mathrm{f}(\mathrm{U})$ & $=\mathrm{f}(\mathrm{P}, \mathrm{I}, \mathrm{M}, \mathrm{U})$ & $\begin{array}{c}\text { Coverage of } \\
\text { Improvement } \\
\text { Possible } \%\end{array}$ \\
\hline Stay & $\mathrm{I}(.728, .836)$ & $\sim \mathrm{P} \cdot \mathrm{I} \cdot \mathrm{U}(.852, .651)$ & 45.59 \\
\hline$\sim$ Stay & $\sim \mathrm{I}(.842, .738)$ & $\mathrm{P} \sim \mathrm{I}(.850, .688)$ & 5.06 \\
\hline Daily & $\mathrm{P}(.796, .739)$ & $\sim \mathrm{P} \cdot \mathrm{I} \cdot \mathrm{M} \cdot \sim \mathrm{U}(.811, .275)$ & 7.35 \\
\hline$\sim$ Daily & $\sim \mathrm{P}(.721, .781)$ & $\sim \mathrm{P} \cdot \mathrm{I} \cdot \mathrm{U}(.840, .633)$ & 42.65 \\
\hline Shop & $\sim \mathrm{I}(.751, .707)$ & $\mathrm{P} \cdot \sim \mathrm{I}(.761, .662)$ & 4.02 \\
\hline$\sim$ Shop & $\sim \mathrm{M}(.742, .572)$ & $\sim \mathrm{P} \cdot \mathrm{I} \cdot \mathrm{U}(.807, .570)$ & 25.19 \\
\hline Visit & $\sim \mathrm{P}(.765, .755)$ & $\sim \mathrm{P} \cdot \mathrm{I} \sim \mathrm{M} \cdot \mathrm{U}(.846, .256)$ & 34.47 \\
\hline$\sim$ Visit & $\mathrm{P}(.750, .760)$ & $\mathrm{P} \cdot \sim \mathrm{I} \cdot \mathrm{M}(.921, .560)$ & 68.40 \\
\hline \multicolumn{2}{r|}{} & Average coverage of improvement possible $\%$ & 29.09 \\
\hline
\end{tabular}

Note. P: power distance; I: individualism; M: masculinity; U: uncertainty avoidance

Table 9: Consistency and coverage scores of the causal fuzzy set relations of the best Inglehart's individual and the configuration of cultural values on the Australian outcome conditions

\begin{tabular}{|c|c|c|c|}
\hline $\begin{array}{c}\text { Outcome } \\
\text { Condition }\end{array}$ & $=\mathrm{f}(\mathrm{T}) ;=\mathrm{f}(\mathrm{S})$ & $=\mathrm{f}(\mathrm{T}, \mathrm{S})$ & $\begin{array}{c}\text { Coverage of } \\
\text { Improvement } \\
\text { Possible } \%\end{array}$ \\
\hline Stay & $\sim \mathrm{S}(.705, .935)$ & $\sim \mathrm{T} \cdot \sim \mathrm{S}(.853, .745)$ & 50.17 \\
\hline$\sim$ Stay & $\mathrm{S}(.925, .671)$ & $\mathrm{T} \cdot \mathrm{S}(.940, .258)$ & 20.00 \\
\hline Daily & $\mathrm{S}(.879, .646)$ & $\sim \mathrm{T} \cdot \mathrm{S}(.894, .542)$ & 12.40 \\
\hline$\sim$ Daily & $\sim \mathrm{S}(.686, .897)$ & $\sim \mathrm{T} \cdot \sim \mathrm{S}(.845, .727)$ & 50.64 \\
\hline Shop & $\mathrm{S}(.845, .659)$ & $\sim \mathrm{T} \cdot \mathrm{S}(.889, .572)$ & 28.39 \\
\hline$\sim$ Shop & $\mathrm{S}(.715, .877)$ & $\sim \mathrm{T} \cdot \sim \mathrm{S}(.836, .675)$ & 42.46 \\
\hline Visit & $\sim \mathrm{S}(.715, .852)$ & $\sim \mathrm{T} \cdot \sim \mathrm{S}(.857, .673)$ & 49.82 \\
\hline$\sim$ Visit & $\mathrm{S}(.810, .649)$ & $\mathrm{T} \cdot \mathrm{S}(.937, .284)$ & 66.84 \\
\hline \multicolumn{2}{|r|}{ Average coverage of improvement possible $\%$} & 40.09 \\
\hline
\end{tabular}

Note. T: traditional; S: survival 
Table 10: Consistency and coverage scores of the causal fuzzy set relations of the best Schwartz's individual and the configuration of cultural values on the Australian outcome conditions

\begin{tabular}{|c|c|c|c|}
\hline $\begin{array}{l}\text { Outcome } \\
\text { Condition }\end{array}$ & $\begin{array}{c}=\mathrm{f}(\mathrm{Aa}) ;=\mathrm{f}(\mathrm{Ia}) ;=\mathrm{f}(\mathrm{Em}) ;=\mathrm{f} \\
(\mathrm{Hi}) ;=\mathrm{f}(\mathrm{Ma}) ;=\mathrm{f}(\mathrm{Eg}) ;=\mathrm{f}(\mathrm{Ha})\end{array}$ & $=\mathrm{f}(\mathrm{Aa}, \mathrm{Ia}, \mathrm{Em}, \mathrm{Hi}, \mathrm{Ma}, \mathrm{Eg}, \mathrm{Ha})$ & $\begin{array}{c}\text { Coverage of } \\
\text { Improvement } \\
\text { Possible \% } \\
\end{array}$ \\
\hline Stay & $\operatorname{Eg}(.854, .763)$ & $\begin{array}{c}\mathrm{Ia} \cdot \sim \mathrm{Em} \cdot \sim \mathrm{Hi} \cdot \sim \mathrm{Ma} \cdot \mathrm{Eg} \cdot \mathrm{Ha} \\
(.983, .469)\end{array}$ & 88.36 \\
\hline$\sim$ Stay & Hi $(.911, .602)$ & $\begin{array}{c}\sim \mathrm{Aa} \cdot \sim \mathrm{Ia} \cdot \mathrm{Em} \cdot \mathrm{Hi} \cdot \sim \mathrm{Ma} \cdot \sim \mathrm{Eg} \cdot \mathrm{Ha} \\
(.989, .277)\end{array}$ & 87.64 \\
\hline Daily & Hi $(.825, .553)$ & $\begin{array}{c}\sim \mathrm{Aa} \cdot \mathrm{Ia} \cdot \sim \mathrm{Em} \cdot \sim \mathrm{Hi} \cdot \mathrm{Ma} \cdot \sim \mathrm{Eg} \cdot \mathrm{Ha} \\
(.974, .207)\end{array}$ & 85.14 \\
\hline Daily & $\operatorname{Eg}(.793, .698)$ & $\begin{array}{c}\mathrm{Ia} \cdot \sim \mathrm{Em} \cdot \sim \mathrm{Hi} \cdot \sim \mathrm{Ma} \cdot \mathrm{Eg} \cdot \mathrm{Ha} \\
(.942, .443)\end{array}$ & 71.98 \\
\hline Shop & Hi $(.772, .548)$ & $\begin{array}{c}\sim \mathrm{Aa} \cdot \sim \mathrm{Ia} \cdot \mathrm{Em} \cdot \mathrm{Hi} \cdot \sim \mathrm{Ma} \cdot \sim \mathrm{Eg} \cdot \mathrm{Ha} \\
(.884, .266)\end{array}$ & 49.12 \\
\hline Shop & $\operatorname{Eg}(.820, .677)$ & $\begin{array}{c}\mathrm{Ia} \cdot \sim \mathrm{Em} \cdot \sim \mathrm{Hi} \cdot \sim \mathrm{Ma} \cdot \mathrm{Eg} \cdot \mathrm{Ha} \\
(.951, .419)\end{array}$ & 72.78 \\
\hline Visit & $\operatorname{Eg}(.848, .681)$ & $\begin{array}{c}\sim \mathrm{Ma} \cdot \mathrm{Eg} \\
(.955, .511)\end{array}$ & 70.39 \\
\hline$\sim$ Visit & Ha (.797, .502) & $\begin{array}{c}\sim \mathrm{Aa} \cdot \mathrm{Ia} \cdot \sim \mathrm{Em} \cdot \sim \mathrm{Hi} \cdot \mathrm{Ma} \cdot \sim \mathrm{Eg} \cdot \mathrm{Ha} \\
(.988, .229)\end{array}$ & 94.09 \\
\hline \multicolumn{3}{|c|}{ Average coverage of improvement possible \% } & 77.44 \\
\hline
\end{tabular}

Note. Aa: affective autonomy; Ia: intellectual autonomy; Em: embeddedness; Hi: hierarchy; M: mastery; Eg: egalitarian; Ha: harmony 
Table 11: Consistency and coverage scores of the causal fuzzy set relations of the best Steenkamp's individual and the configuration of cultural values on the Australian outcome conditions

\begin{tabular}{|c|c|c|c|}
\hline $\begin{array}{c}\text { Outcome } \\
\text { Condition }\end{array}$ & $=\mathrm{f}(\mathrm{A}) ;=\mathrm{f}(\mathrm{E}) ;=\mathrm{f}(\mathrm{M}) ;=\mathrm{f}(\mathrm{U})$ & $=\mathrm{f}(\mathrm{A}, \mathrm{E}, \mathrm{M}, \mathrm{U})$ & $\begin{array}{c}\text { Coverage of } \\
\text { Improvement } \\
\text { Possible } \%\end{array}$ \\
\hline Stay & $\mathrm{E}(.936, .586)$ & $\mathrm{A} \cdot \mathrm{E} \cdot \sim \mathrm{M} \cdot \sim \mathrm{U}(.950, .347)$ & 21.87 \\
\hline$\sim$ Stay & $\sim \mathrm{A}(.808, .767)$ & $\sim \mathrm{A} \cdot \sim \mathrm{E} \cdot \sim \mathrm{M}(.872, .513)$ & 33.33 \\
\hline Daily & $\sim \mathrm{A}(.766, .736)$ & $\sim \mathrm{A} \cdot \sim \mathrm{E} \cdot \sim \mathrm{M}(.848, .506)$ & 35.04 \\
\hline$\sim$ Daily & $\mathrm{E}(.958, .591)$ & $\mathrm{A} \cdot \mathrm{E} \cdot \mathrm{M} \cdot \mathrm{U}(.989, .324)$ & 73.81 \\
\hline Shop & $\sim \mathrm{A}(.688, .702)$ & $\sim \mathrm{A} \cdot \sim \mathrm{E} \cdot \sim \mathrm{M} \cdot \mathrm{U}(.810, .298)$ & 39.10 \\
\hline$\sim$ Shop & $\mathrm{E}(.897, .519)$ & $\mathrm{A} \cdot \mathrm{E} \cdot \sim \mathrm{M} \cdot \sim \mathrm{U}(.972, .328)$ & 72.82 \\
\hline Visit & $\mathrm{E}(.893, .502)$ & $\sim \mathrm{A} \cdot \sim \mathrm{M}(.918, .390)$ & 23.36 \\
\hline$\sim$ Visit & $\sim \mathrm{A}(.724, .759)$ & $\sim \mathrm{A} \cdot \sim \mathrm{E} \cdot \sim \mathrm{U}(.788, .607)$ & 23.19 \\
\hline \multicolumn{2}{|c|}{ Average coverage of improvement possible $\%$} & 40.32 \\
\hline
\end{tabular}

A: autonomy; E: egalitarianism; M: mastery; U: uncertainty avoidance

Table 12: Consistency and coverage scores of the causal fuzzy set relations of the best Hofstede's individual and the configuration of cultural values on the American outcome conditions

\begin{tabular}{|c|c|c|c|}
\hline $\begin{array}{l}\text { Outcome } \\
\text { Condition }\end{array}$ & $=\mathrm{f}(\mathrm{P}) ;=\mathrm{f}(\mathrm{I}) ;=\mathrm{f}(\mathrm{M}) ;=\mathrm{f}(\mathrm{U})$ & $=f(P, I, M, U)$ & $\begin{array}{c}\text { Coverage of } \\
\text { Improvement } \\
\text { Possible \% }\end{array}$ \\
\hline Stay & $\sim \mathrm{U}(.907, .446)$ & $\sim \mathrm{P} \cdot \mathrm{I} \cdot \mathrm{M} \cdot \sim \mathrm{U}(1.000, .221)$ & 100 \\
\hline$\sim$ Stay & $\sim \mathrm{I}(.503, .683)$ & $\mathrm{P} \cdot \sim \mathrm{I} \cdot \mathrm{M} \cdot \mathrm{U}(.837, .538)$ & 67.2 \\
\hline Plan & $\sim \mathrm{P}(.891, .732)$ & $\mathrm{I} \cdot \sim \mathrm{M} \cdot \mathrm{U}(.946, .427)$ & 50.46 \\
\hline$\sim$ Plan & $\sim \mathrm{I}(.836, .832)$ & $\sim \mathrm{I} \cdot \mathrm{M} \cdot \mathrm{U}(.946, .446)$ & 67.07 \\
\hline Shop & $\sim \mathrm{I}(.954, .557)$ & $P \cdot \sim I(.972, .527)$ & 39.13 \\
\hline$\sim$ Shop & $\sim \mathrm{P}(.508, .865)$ & $\sim \mathrm{P} \cdot \mathrm{I} \cdot \sim \mathrm{M} \cdot \mathrm{U}(.745, .482)$ & 48.17 \\
\hline Visit & $\sim \mathrm{U}(.961, .465)$ & $\mathrm{P} \cdot \sim \mathrm{I} \cdot \sim \mathrm{U}(.976, .285)$ & 38.46 \\
\hline$\sim$ Visit & $\mathrm{P}(.510, .897)$ & $\mathrm{P} \cdot \sim \mathrm{I} \cdot \mathrm{U}(.795, .671)$ & 58.16 \\
\hline \multicolumn{3}{|c|}{ Average coverage of improvement possible \% } & 58.58 \\
\hline
\end{tabular}

Note. P: power distance; I: individualism; M: masculinity; U: uncertainty avoidance 
Table 13: Consistency and coverage scores of the causal fuzzy set relations of the best Inglehart's individual and the configuration of cultural values on the American outcome conditions

\begin{tabular}{|c|c|c|c|}
\hline $\begin{array}{c}\text { Outcome } \\
\text { Condition }\end{array}$ & $=\mathrm{f}(\mathrm{T}) ;=\mathrm{f}(\mathrm{S})$ & $=\mathrm{f}(\mathrm{T}, \mathrm{S})$ & $\begin{array}{c}\text { Coverage of } \\
\text { Improvement } \\
\text { Possible } \%\end{array}$ \\
\hline Stay & $\mathrm{T}(.986, .505)$ & $\mathrm{T} \cdot \sim \mathrm{S}(1.000, .448)$ & 100 \\
\hline$\sim$ Stay & $\mathrm{S}(.697, .637)$ & $\sim \mathrm{T} \cdot \mathrm{S}(.805, .621)$ & 36.64 \\
\hline Plan & $\sim \mathrm{S}(.771, .957)$ & $\sim \mathrm{T} \cdot \mathrm{S}(.890, .785)$ & 51.97 \\
\hline$\sim$ Plan & $\mathrm{S}(.912, .611)$ & $\mathrm{T} \cdot \mathrm{S}(1.000, .345)$ & 0 \\
\hline Shop & $\mathrm{T}(1.000, .490)$ & $\mathrm{T} \cdot \mathrm{S}(1.000, .202)$ & 21.75 \\
\hline$\sim$ Shop & $\sim \mathrm{T}(.430,1.000)$ & $\mathrm{T} \cdot \mathrm{S}(.554, .290)$ & 100 \\
\hline Visit & $\mathrm{T}(.946, .477)$ & $\sim \mathrm{T} \cdot \mathrm{S}(.791, .600, .208)$ & 30.33 \\
\hline$\sim$ Visit & $\mathrm{S}(.700, .663)$ & 54.96 \\
\hline \multicolumn{2}{|c|}{ Average coverage of improvement possible $\%$} & \\
\hline
\end{tabular}

Note. T: traditional; S: survival 
Table 14: Consistency and coverage scores of the causal fuzzy set relations of the best

Schwartz's individual and the configuration of cultural values on the American outcome conditions

\begin{tabular}{|c|c|c|c|}
\hline $\begin{array}{l}\text { Outcome } \\
\text { Condition }\end{array}$ & $\begin{array}{c}=\mathrm{f}(\mathrm{Aa}) ;=\mathrm{f}(\mathrm{Ia}) ;=\mathrm{f}(\mathrm{Em}) ;=\mathrm{f} \\
(\mathrm{Hi}) ;=\mathrm{f}(\mathrm{Ma}) ;=\mathrm{f}(\mathrm{Eg}) ;=\mathrm{f}(\mathrm{Ha})\end{array}$ & $=\mathrm{f}(\mathrm{Aa}, \mathrm{Ia}, \mathrm{Em}, \mathrm{Hi}, \mathrm{Ma}, \mathrm{Eg}, \mathrm{Ha})$ & $\begin{array}{c}\text { Coverage of } \\
\text { Improvement } \\
\text { Possible \% } \\
\end{array}$ \\
\hline Stay & Ha (.989, .110) & $\begin{array}{c}\mathrm{Aa} \cdot \mathrm{Ia} \cdot \sim \mathrm{Em} \cdot \sim \mathrm{Hi} \cdot \mathrm{Ma} \cdot \mathrm{Eg} \cdot \mathrm{Ha} \\
(1.000, .251)\end{array}$ & 100 \\
\hline$\sim$ Stay & Ma $(.583, .626)$ & $\begin{array}{c}\sim \mathrm{Aa} \cdot \mathrm{Ia} \cdot \sim \mathrm{Em} \cdot \sim \mathrm{Hi} \cdot \mathrm{Ma} \cdot \sim \mathrm{Eg} \cdot \mathrm{Ha} \\
(.755, .223)\end{array}$ & 41.25 \\
\hline Plan & Ma $(.813, .469)$ & $\begin{array}{c}\sim \mathrm{Aa} \cdot \sim \mathrm{Ia} \cdot \mathrm{Em} \cdot \sim \mathrm{Hi} \cdot \sim \mathrm{Ma} \cdot \sim \mathrm{Eg} \cdot \mathrm{Ha} \\
(1.000, .163)\end{array}$ & 100 \\
\hline$\sim$ Plan & Ha $(.924, .168)$ & $\begin{array}{c}\sim \mathrm{Aa} \cdot \sim \mathrm{Ia} \cdot \mathrm{Em} \cdot \mathrm{Hi} \cdot \sim \mathrm{Ma} \cdot \sim \mathrm{Eg} \cdot \mathrm{Ha} \\
(.952, .389)\end{array}$ & 36.84 \\
\hline Shop & $\sim$ Ha $(1.000, .106)$ & $\begin{array}{c}\sim \mathrm{Aa} \cdot \sim \mathrm{Ia} \cdot \mathrm{Em} \cdot \sim \mathrm{Ma} \cdot \sim \mathrm{Eg} \cdot \mathrm{Ha} \\
(1.000, .308)\end{array}$ & 0 \\
\hline Shop & Em (.461, .997) & $\begin{array}{c}\sim \mathrm{Aa} \cdot \sim \mathrm{Ia} \cdot \mathrm{Em} \cdot \mathrm{Hi} \cdot \mathrm{Ma} \cdot \sim \mathrm{Eg} \cdot \sim \mathrm{Ha} \\
(.714, .075)\end{array}$ & 46.94 \\
\hline Visit & Ha $(1.000, .109)$ & $\begin{array}{c}\mathrm{Aa} \cdot \mathrm{Ia} \cdot \sim \mathrm{Em} \cdot \sim \mathrm{Hi} \cdot \mathrm{Ma} \cdot \mathrm{Eg} \cdot \mathrm{Ha} \\
(1.000, .247)\end{array}$ & 0 \\
\hline$\sim$ Visit & Hi $(.603, .671)$ & $\begin{array}{c}\sim \mathrm{Aa} \cdot \mathrm{Ia} \cdot \sim \mathrm{Em} \cdot \sim \mathrm{Hi} \cdot \mathrm{Ma} \cdot \sim \mathrm{Eg} \cdot \mathrm{Ha} \\
(.782, .240)\end{array}$ & 45.09 \\
\hline \multicolumn{3}{|c|}{ Average coverage of improvement possible \% } & 46.26 \\
\hline
\end{tabular}

Aa: affective autonomy; Ia: intellectual autonomy; Em: embeddedness; Hi: hierarchy; M: mastery; Eg: egalitarian; Ha: harmony 
Table 15: Consistency and coverage scores of the causal fuzzy set relations of the best Steenkamp's individual and the configuration of cultural values on the American outcome conditions

\begin{tabular}{|c|c|c|c|}
\hline $\begin{array}{c}\text { Outcome } \\
\text { Condition }\end{array}$ & $=\mathrm{f}(\mathrm{A}) ;=\mathrm{f}(\mathrm{E}) ;=\mathrm{f}(\mathrm{M}) ;=\mathrm{f}(\mathrm{U})$ & $=\mathrm{f}(\mathrm{A}, \mathrm{E}, \mathrm{M}, \mathrm{U})$ & $\begin{array}{c}\text { Coverage of } \\
\text { Improvement } \\
\text { Possible } \%\end{array}$ \\
\hline Stay & $\sim \mathrm{U}(.947, .564)$ & $\mathrm{E} \cdot \mathrm{M} \cdot \mathrm{U}(1.000, .306)$ & 100 \\
\hline$\sim$ Stay & $\mathrm{U}(.489, .903)$ & $\mathrm{A} \sim \mathrm{E} \cdot \mathrm{U}(.762, .575)$ & 53.42 \\
\hline Plan & $\mathrm{E}(.841, .641)$ & $\mathrm{A} \cdot \sim \mathrm{E} \cdot \mathrm{M}(.943, .453)$ & 64.15 \\
\hline$\sim$ Plan & $\sim \mathrm{A}(.778, .773)$ & $\sim \mathrm{A} \cdot \sim \mathrm{E} \cdot \mathrm{M}(.821, .588)$ & 19.37 \\
\hline Shop & $\sim \mathrm{A}(.970, .565)$ & $\mathrm{A} \cdot \sim \mathrm{E} \cdot \mathrm{M}(1.000, .385)$ & 100 \\
\hline$\sim$ Shop & $\mathrm{E}(.566, .895)$ & $\mathrm{A} \cdot \mathrm{E} \cdot \mathrm{M} \cdot \mathrm{U}(.760, .521)$ & 44.70 \\
\hline Visit & $\sim \mathrm{U}(.980, .574)$ & $\mathrm{E} \cdot \mathrm{M} \cdot \mathrm{U}(1.000, .301)$ & 100 \\
\hline$\sim$ Visit & $\mathrm{U}(.494, .972)$ & $\mathrm{A} \cdot \sim \mathrm{E} \cdot \mathrm{U}(.815, .638)$ & 63.44 \\
\hline \multicolumn{2}{|c|}{ Average coverage of improvement possible $\%$} & 68.14 \\
\hline
\end{tabular}

A: autonomy; E: egalitarianism; M: mastery; U: uncertainty avoidance.

Table 16: Representative Cultural Configurations by Hofstede’s Theory

\begin{tabular}{|c|c|}
\hline Country & Representative cultural configuration \\
\hline Australia/Germany/Switzerland & $\sim \mathrm{P} \cdot \mathrm{I} \cdot \mathrm{M} \cdot \mathrm{U}$ \\
\hline Brazil/Taiwan & $\mathrm{P} \sim \mathrm{I} \cdot \sim \mathrm{M} \cdot \mathrm{U}$ \\
\hline France/Spain & $\mathrm{P} \cdot \mathrm{I} \sim \mathrm{M} \cdot \mathrm{U}$ \\
\hline Hong Kong/Malaysia 1 & $\mathrm{P} \sim \mathrm{I} \cdot \mathrm{M} \cdot \sim \mathrm{U}$ \\
\hline Italy & $\mathrm{P} \sim \mathrm{I} \cdot \mathrm{M} \cdot \sim \mathrm{U}$ \\
\hline Japan & $\mathrm{P} \cdot \sim \mathrm{I} \cdot \mathrm{M} \cdot \mathrm{U}$ \\
\hline Netherlands & $\sim \mathrm{P} \cdot \mathrm{I} \sim \sim \mathrm{M} \cdot \mathrm{U}$ \\
\hline New Zealand/USA & $\sim \mathrm{P} \cdot \mathrm{I} \cdot \mathrm{M} \cdot \sim \mathrm{U}$ \\
\hline Singapore/Malaysia 2 & $\mathrm{P} \cdot \sim \mathrm{I} \cdot \sim \mathrm{M} \cdot \sim \mathrm{U}$ \\
\hline
\end{tabular}

P: power distance; I: individualism; M: masculinity; U: uncertainty avoidance 
Table 17: Representative Cultural Configurations by Inglehart's Theory

\begin{tabular}{|c|c|}
\hline Country & Representative Cultural Value Configuration \\
\hline $\begin{array}{c}\text { Australia/France/Germany/Italy/Netherlands/ } \\
\text { New Zealand 1/Spain/Switzerland }\end{array}$ & $\sim \mathrm{T} \sim \mathrm{S}$ \\
\hline Brazil/Malaysia/New Zealand 2/USA & $\mathrm{T} \cdot \sim \mathrm{S}$ \\
\hline Hong Kong/Japan/Taiwan & $\sim \mathrm{T} \cdot \mathrm{S}$ \\
\hline Singapore & $\mathrm{T} \cdot \mathrm{S}$ \\
\hline
\end{tabular}

T: traditional; S: survival

Table 18: Representative Cultural Configurations by Schwartz's Theory

\begin{tabular}{|c|c|}
\hline Country & Representative Cultural Value Configuration \\
\hline \multirow{4}{*}{ Australia } & $\sim \mathrm{Aa} \cdot \sim \mathrm{Ia} \cdot \sim \mathrm{Em} \cdot \sim \mathrm{Hi} \cdot \sim \mathrm{Ma} \cdot \mathrm{Eg} \cdot \mathrm{Ha}$ \\
\hline & $\sim \mathrm{Aa} \cdot \sim \mathrm{Ia} \cdot \sim \mathrm{Em} \cdot \sim \mathrm{Hi} \cdot \sim \mathrm{Ma} \cdot \sim \mathrm{Eg} \cdot \mathrm{Ha}$ \\
\hline & Aa: Ia・ Em? $\mathrm{Hi} \sim \sim \mathrm{Ma} \cdot \mathrm{Eg} \cdot \mathrm{Ha}$ \\
\hline & $\mathrm{Aa} \cdot \sim \mathrm{Ia} \cdot \sim \mathrm{Em} \cdot \sim \mathrm{Hi} \cdot \sim \mathrm{Ma} \cdot \sim \mathrm{Eg} \cdot \mathrm{Ha}$ \\
\hline Brazil 1 & $\sim \mathrm{Aa} \cdot \sim \mathrm{Ia} \cdot \mathrm{Em} \cdot \mathrm{Hi} \cdot \mathrm{Ma} \cdot \sim \mathrm{Eg} \cdot \mathrm{Ha}$ \\
\hline Brazil 2/Singapore/Taiwan & $\sim \mathrm{Aa} \sim \sim \mathrm{Ia} \cdot \mathrm{Em} \cdot \mathrm{Hi} \sim \sim \mathrm{Ma} \cdot \sim \mathrm{Eg} \cdot \mathrm{Ha}$ \\
\hline France/Germany/Spain & Аa $\cdot \mathrm{Ia} \sim \mathrm{Em} \cdot \sim \mathrm{Hi} \sim \sim \mathrm{Ma} \cdot \mathrm{Eg} \cdot \mathrm{Ha}$ \\
\hline Hong Kong & $\sim \mathrm{Aa} \cdot \sim \mathrm{Ia} \cdot \mathrm{Em} \cdot \mathrm{Hi} \cdot \mathrm{Ma} \cdot \sim \mathrm{Eg} \cdot \sim \mathrm{Ha}$ \\
\hline Italy/Netherlands & $\sim \mathrm{Aa} \cdot \mathrm{Ia} \cdot \sim \mathrm{Em} \sim \sim \mathrm{Hi} \sim \sim \mathrm{Ma} \cdot \mathrm{Eg} \cdot \mathrm{Ha}$ \\
\hline Japan & $\sim \mathrm{Aa} \cdot \mathrm{Ia} \cdot \sim \mathrm{Em} \sim \sim \mathrm{Hi} \cdot \mathrm{Ma} \cdot \sim \mathrm{Eg} \cdot \mathrm{Ha}$ \\
\hline \multirow{2}{*}{ Malaysia } & $\sim \mathrm{Aa} \cdot \sim \mathrm{Ia} \cdot \mathrm{Em} \cdot \sim \mathrm{Hi} \cdot \mathrm{Ma} \cdot \sim \mathrm{Eg} \cdot \sim \mathrm{Ha}$ \\
\hline & $\sim \mathrm{Aa} \cdot \sim \mathrm{Ia} \cdot \sim \mathrm{Em} \sim \sim \mathrm{Hi} \cdot \mathrm{Ma} \cdot \sim \mathrm{Eg} \cdot \sim \mathrm{Ha}$ \\
\hline New Zealand/Switzerland & $\mathrm{Aa} \cdot \mathrm{Ia} \cdot \sim \mathrm{Em} \cdot \sim \mathrm{Hi} \cdot \mathrm{Ma} \cdot \mathrm{Eg} \cdot \mathrm{Ha}$ \\
\hline \multirow{4}{*}{ USA } & Аa $\sim \mathrm{Ia} \cdot \mathrm{Em} \cdot \sim \mathrm{Hi} \cdot \mathrm{Ma} \cdot \sim \mathrm{Eg} \cdot \mathrm{Ha}$ \\
\hline & $\mathrm{Aa} \sim \sim \mathrm{Ia} \cdot \mathrm{Em} \sim \mathrm{Hi} \cdot \mathrm{Ma} \sim \mathrm{Eg} \cdot \sim \mathrm{Ha}$ \\
\hline & Aa $\sim$ Ia $\sim$ Em $\sim \mathrm{Hi} \cdot \mathrm{Ma} \sim \sim \mathrm{Eg} \cdot \mathrm{Ha}$ \\
\hline & $\mathrm{Aa} \cdot \sim \mathrm{Ia} \cdot \sim \mathrm{Em} \cdot \sim \mathrm{Hi} \cdot \mathrm{Ma} \cdot \sim \mathrm{Eg} \cdot \sim \mathrm{Ha}$ \\
\hline
\end{tabular}

Aa: affective autonomy; Ia: intellectual autonomy; Em: embeddedness; Hi: hierarchy; Ma:

mastery; Eg: egalitarian; Ha: harmony

Table 19: Representative Cultural Configurations by Steenkamp's Theory

\begin{tabular}{|c|c|}
\hline Country & Representative Cultural Value Configuration \\
\hline Australia/New Zealand/USA & $\mathrm{A} \cdot \mathrm{E} \cdot \mathrm{M} \cdot \sim \mathrm{U}$ \\
\hline Brazil/Taiwan & $\sim \mathrm{A} \cdot \sim \mathrm{E} \cdot \sim \mathrm{M} \cdot \mathrm{U}$ \\
\hline France/Germany 1/Spain & $\mathrm{A} \cdot \mathrm{E} \cdot \sim \mathrm{M} \cdot \mathrm{U}$ \\
\hline Germany 2/Switzerland & $\mathrm{A} \cdot \mathrm{E} \cdot \mathrm{M} \cdot \mathrm{U}$ \\
\hline Hong Kong/Malaysia & $\sim \mathrm{A} \cdot \sim \mathrm{E} \cdot \mathrm{M} \cdot \sim \mathrm{U}$ \\
\hline Italy & $\sim \mathrm{A} \cdot \mathrm{E} \cdot \mathrm{M} \cdot \mathrm{U}$ \\
\hline Japan & $\mathrm{A} \cdot \sim \mathrm{E} \cdot \mathrm{M} \cdot \mathrm{U}$ \\
\hline Netherlands & $\mathrm{A} \cdot \mathrm{E} \cdot \sim \mathrm{M} \cdot \sim \mathrm{U}$ \\
\hline Singapore & $\sim \mathrm{A} \cdot \sim \mathrm{E} \cdot \sim \mathrm{M} \cdot \sim \mathrm{U}$ \\
\hline
\end{tabular}

A: autonomy; E: egalitarianism; M: mastery; U: uncertainty avoidance. 
Figure 1: The Conceptual Framework of Culture's Influences on International Tourism

\footnotetext{
1. Cultural value orientations

$\sqcup$ Hofstede

- P: power distance

- $\mathrm{T}$ : individualism/collectivism

- M: masculinity/femininity

- U: uncertainty avoidance

Inglchart

- T: traditional/secular-relational

- $\quad$ S: survival/self-expression

$\sqcup$ Schwarlz

- Aa: affective autonomy

- Ia: intellectual autonomy

- Em: embeddedness

- Hi: hierarchy

- Ma: mastery

- Lig: egalitarianism

- Ila: hamnorly

口 Sleenkamp

- A: altonomy/collectivism

- F: cgalitarianism/hicrarchy

- M: mastcry/nurturance

- U: uncertainly Avoidanec

2. Demographics

G GDP per capila

D Dislance
}

3. Consumption moderating variables

$\square$ l'rime motive for trip:

-Holiday only

-VFR

$\square$ Prior visil experience

5. Pre-consumption cognitions and behaviour

- Amount of pre-trip planning

6. Consumption behaviours during visiting Australia and USA

$\sqcup$ I.cngth of stay

$\sqcup$ Daily trip expenditure

Shopping expenditure

4. Subcultural dimensions $\square$ Age

- Young ( $<30)$

- Middle (30 -19)

- Old (50+) $\square$ \# of places visited 
Figure 2

Meta-Analysis of Consistency Averages of Best Fitting Models of Four Theories and G•D for Grouped Data of Visitors to Australia

(Range Covering \pm 1.96 Average Values for Consistency Estimates $>$ 0.749)

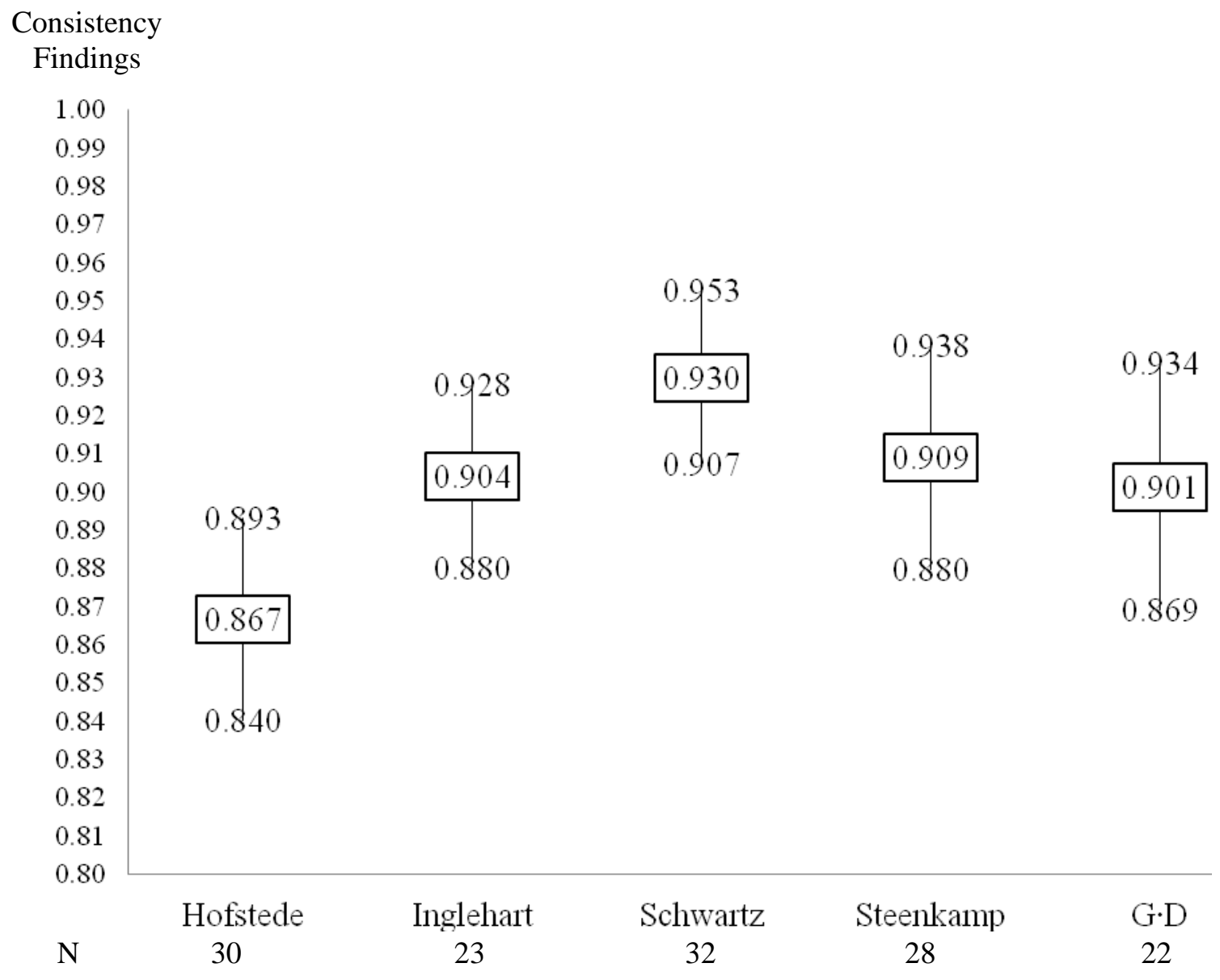


Figure 3

Meta-Analysis of Consistency Averages of Best Fitting Models of Four Theories and G•D for Grouped Data of Visitors to USA

(Range Covering \pm 1.96 Average Values for Consistency Estimates $>$ 0.749)

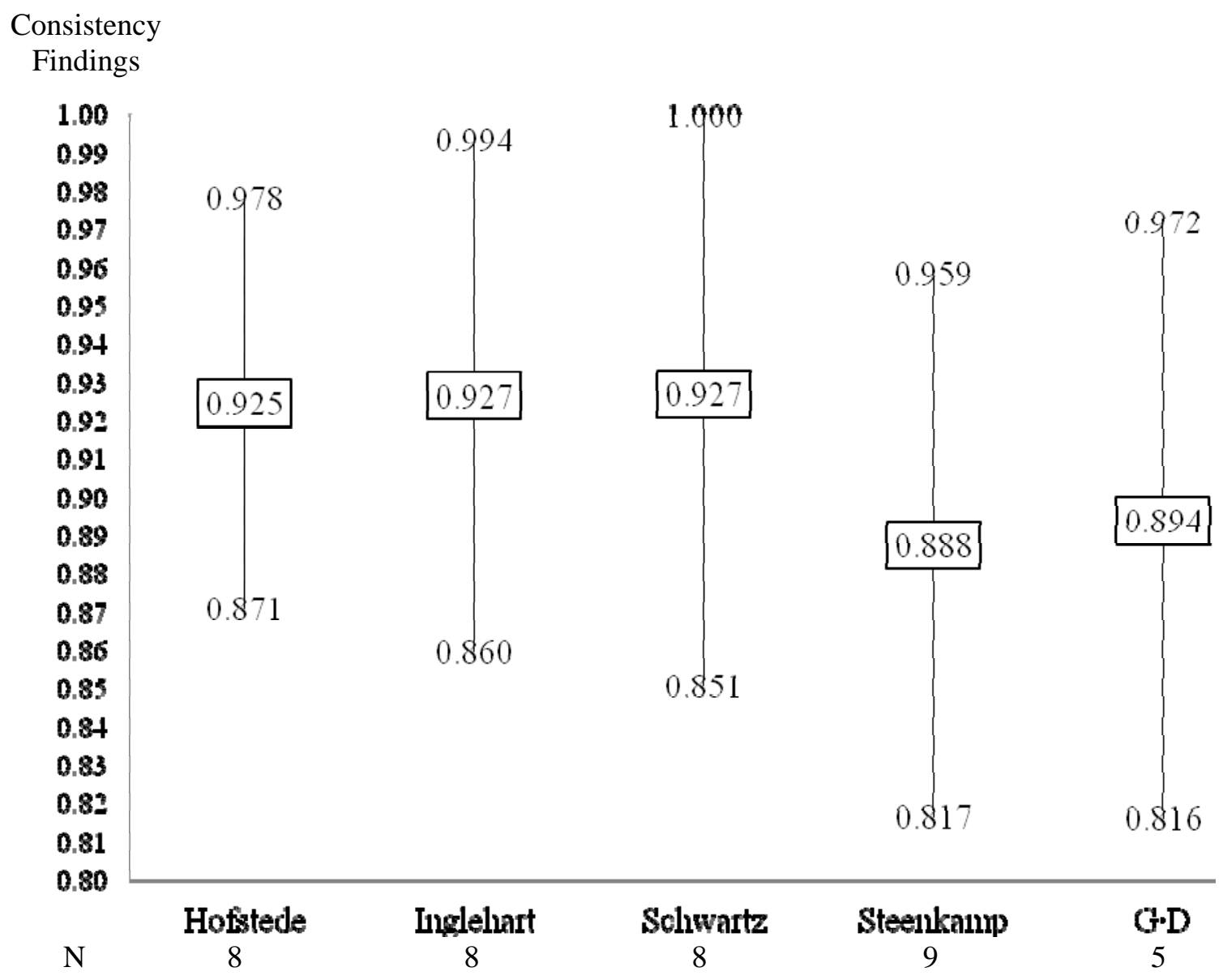




\section{Figure 4}

Meta-Analysis of Consistency Averages of Hofstede's Best Fitting Models by Four Purposes for Grouped Data of Visitors to Australia

(Range Covering \pm 1.96 Average Values for Consistency Estimates $>$ 0.749)

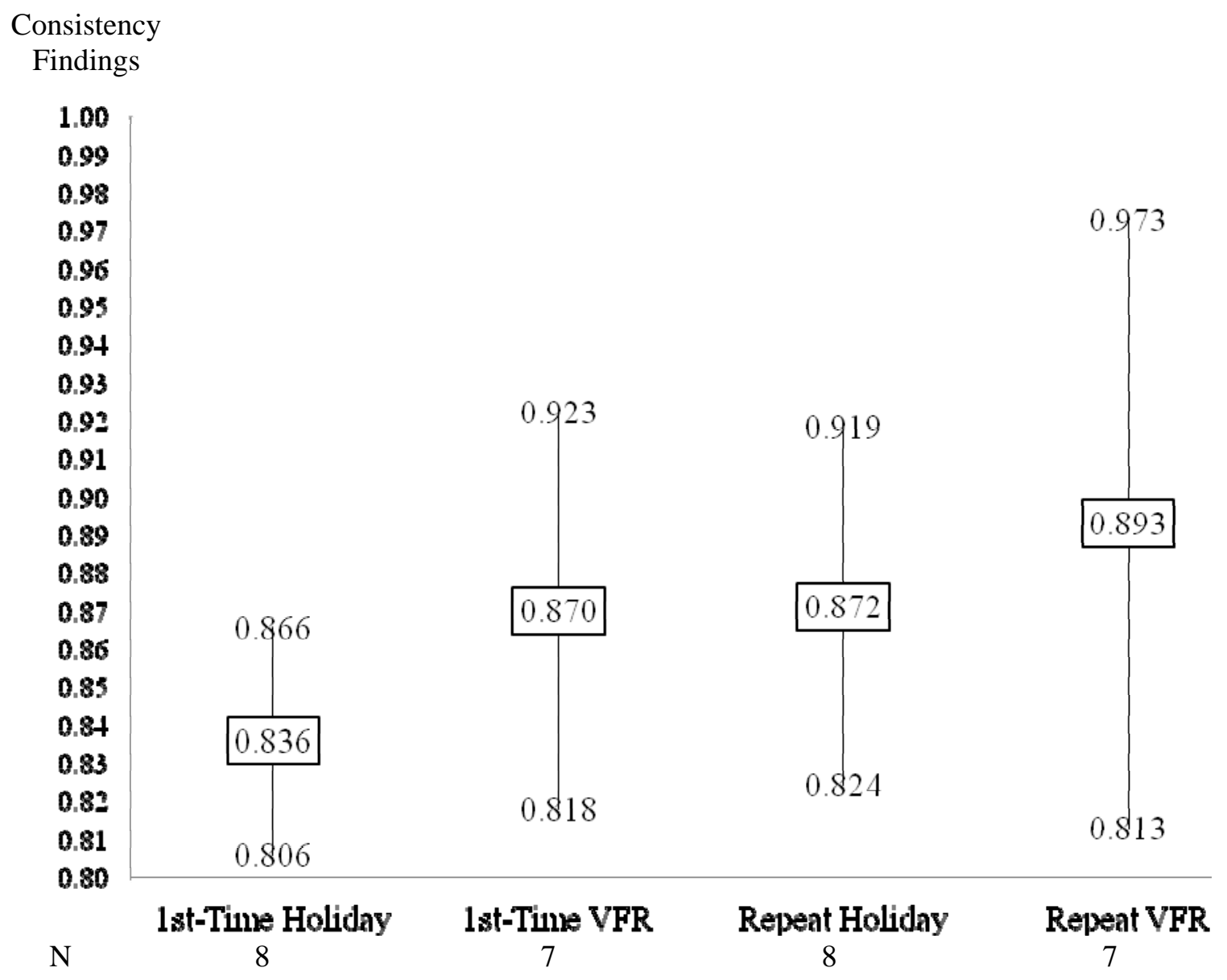


Figure 5

Meta-Analysis of Consistency Averages of Inglehart's Best Fitting Models by Four

Purposes for Grouped Data of Visitors to Australia

(Range Covering \pm 1.96 Average Values for Consistency Estimates $>$ 0.749)

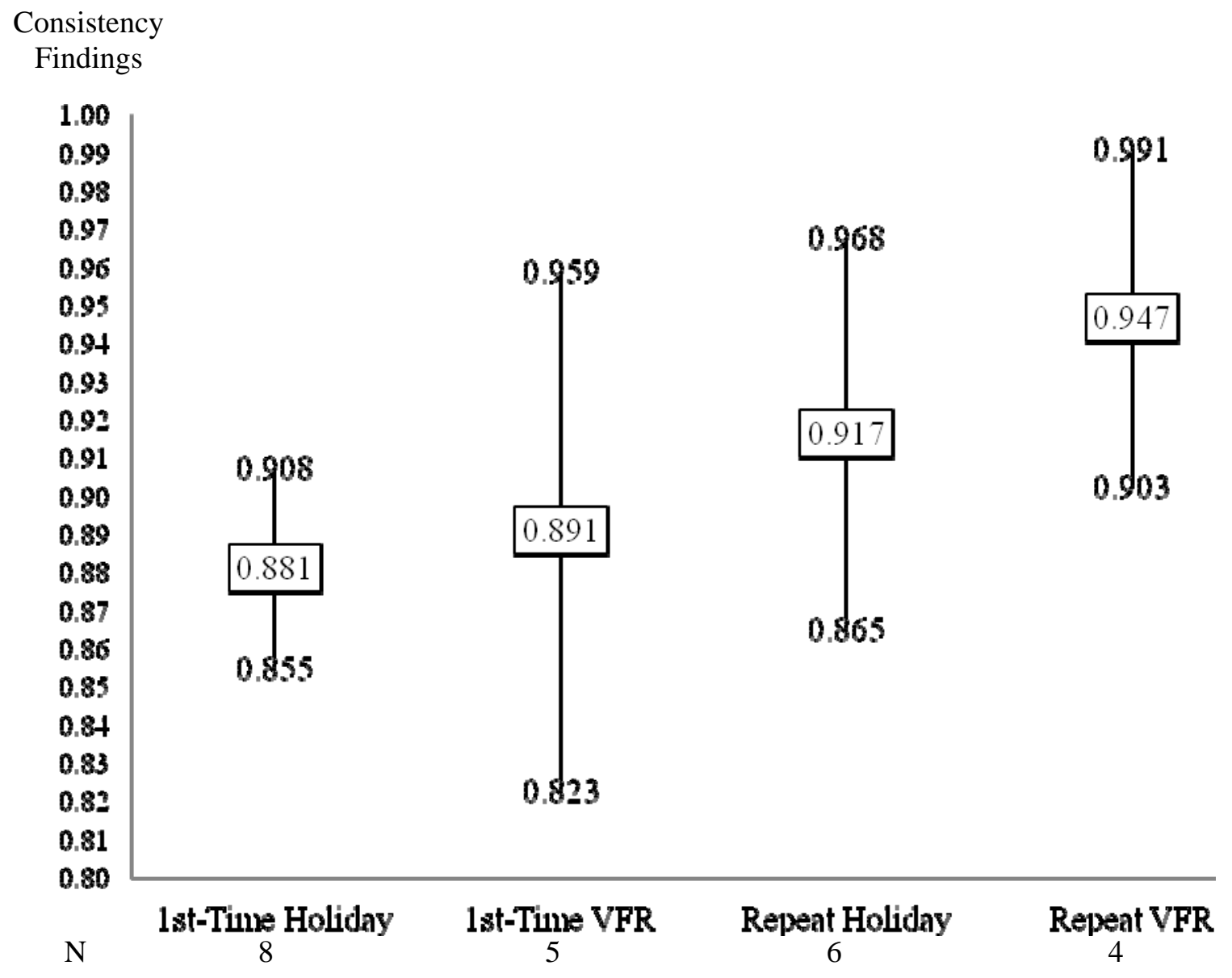


Figure 6

Meta-Analysis of Consistency Averages of Schwartz's Best Fitting Models by Four

Purposes for Grouped Data of Visitors to Australia

(Range Covering \pm 1.96 Average Values for Consistency Estimates > 0.749)

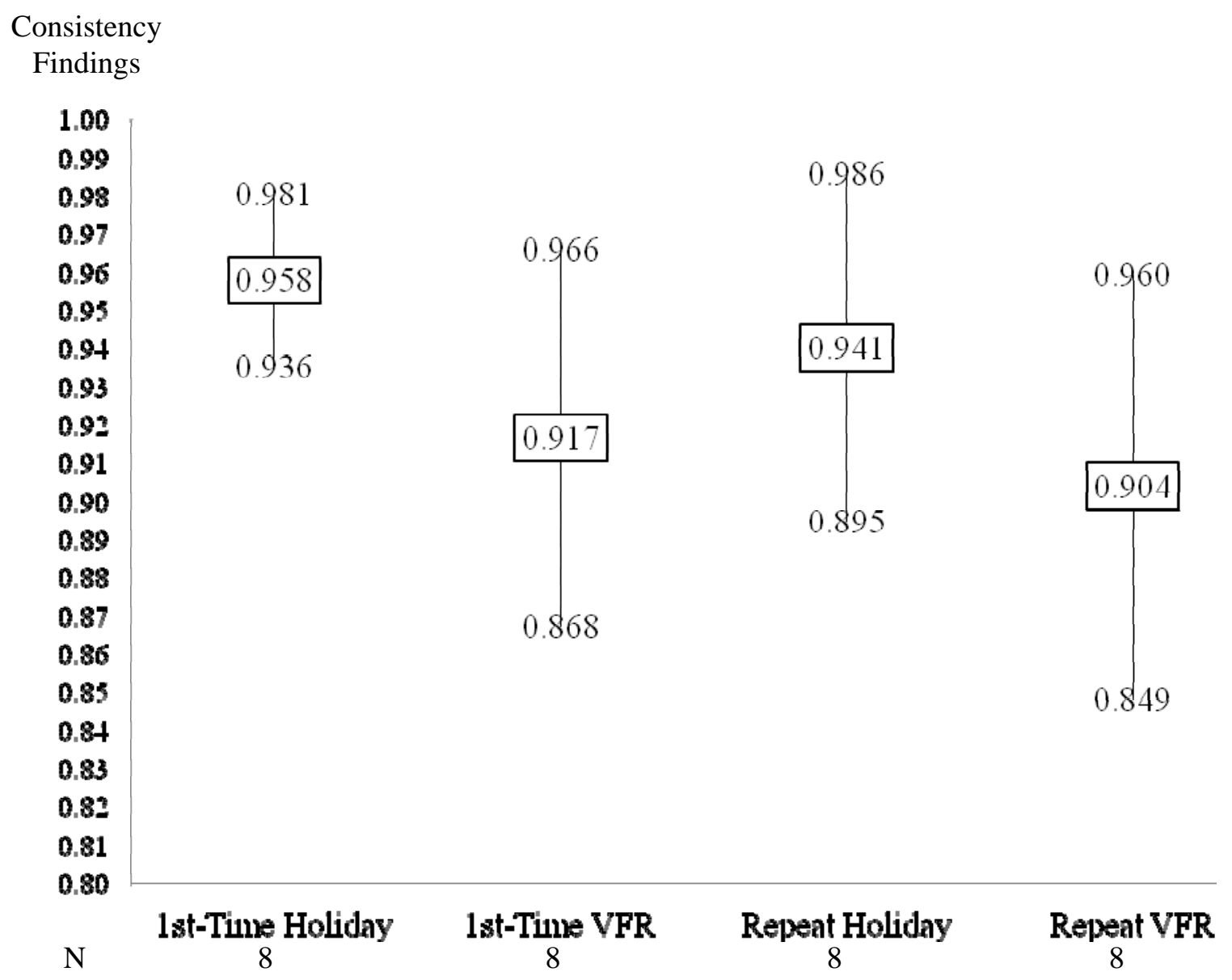


Figure 7

Meta-Analysis of Consistency Averages of Steenkamp's Best Fitting Models by Four Purposes for Grouped Data of Visitors to Australia

(Range Covering \pm 1.96 Average Values for Consistency Estimates $>$ 0.749)

\section{Consistency \\ Findings}

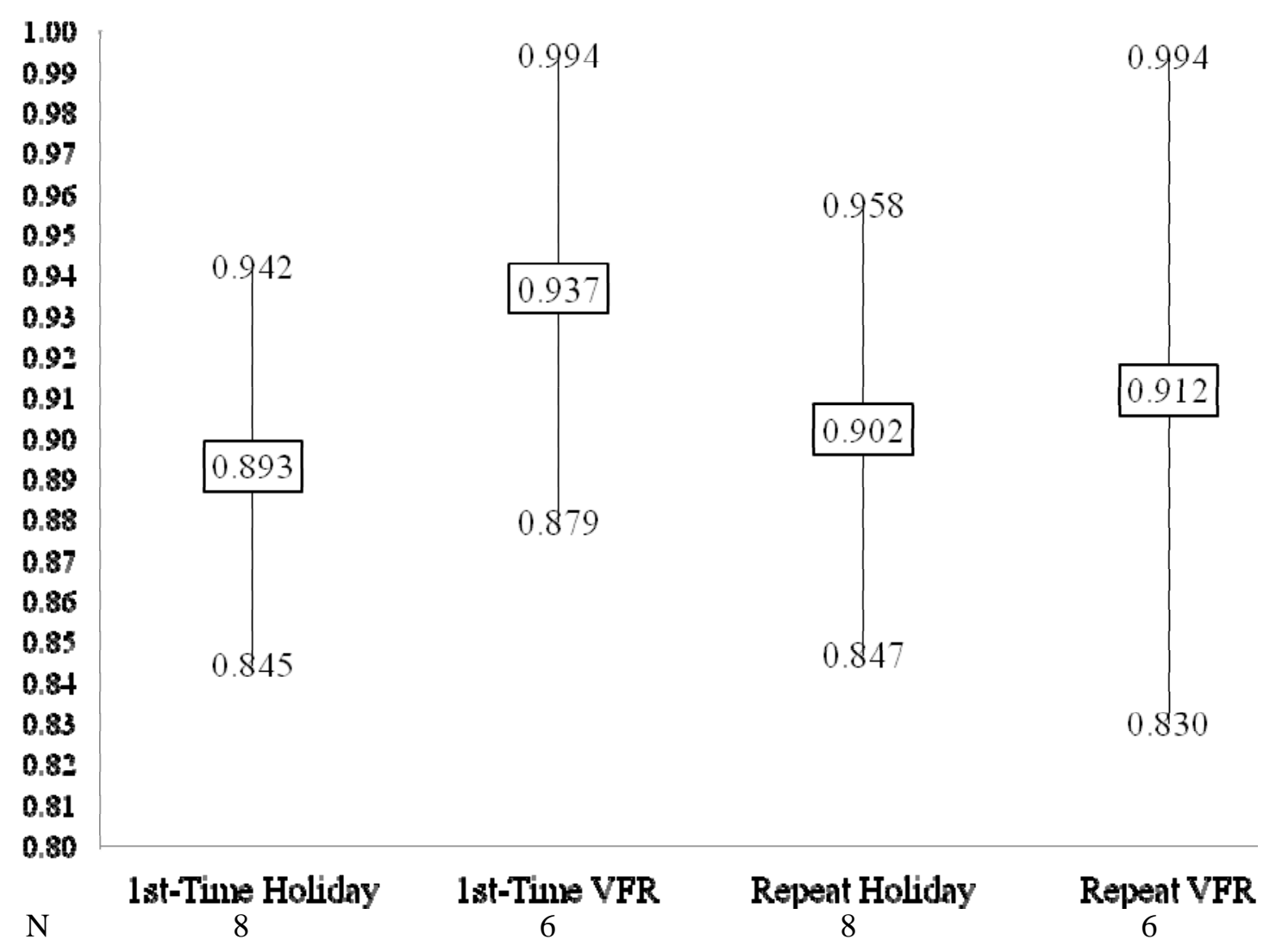


Figure 8

Meta-Analysis of Consistency Averages of Best G·D Fitting Models by Four Purposes for Grouped Data of Visitors to Australia

(Range Covering \pm 1.96 Average Values for Consistency Estimates > 0.749)

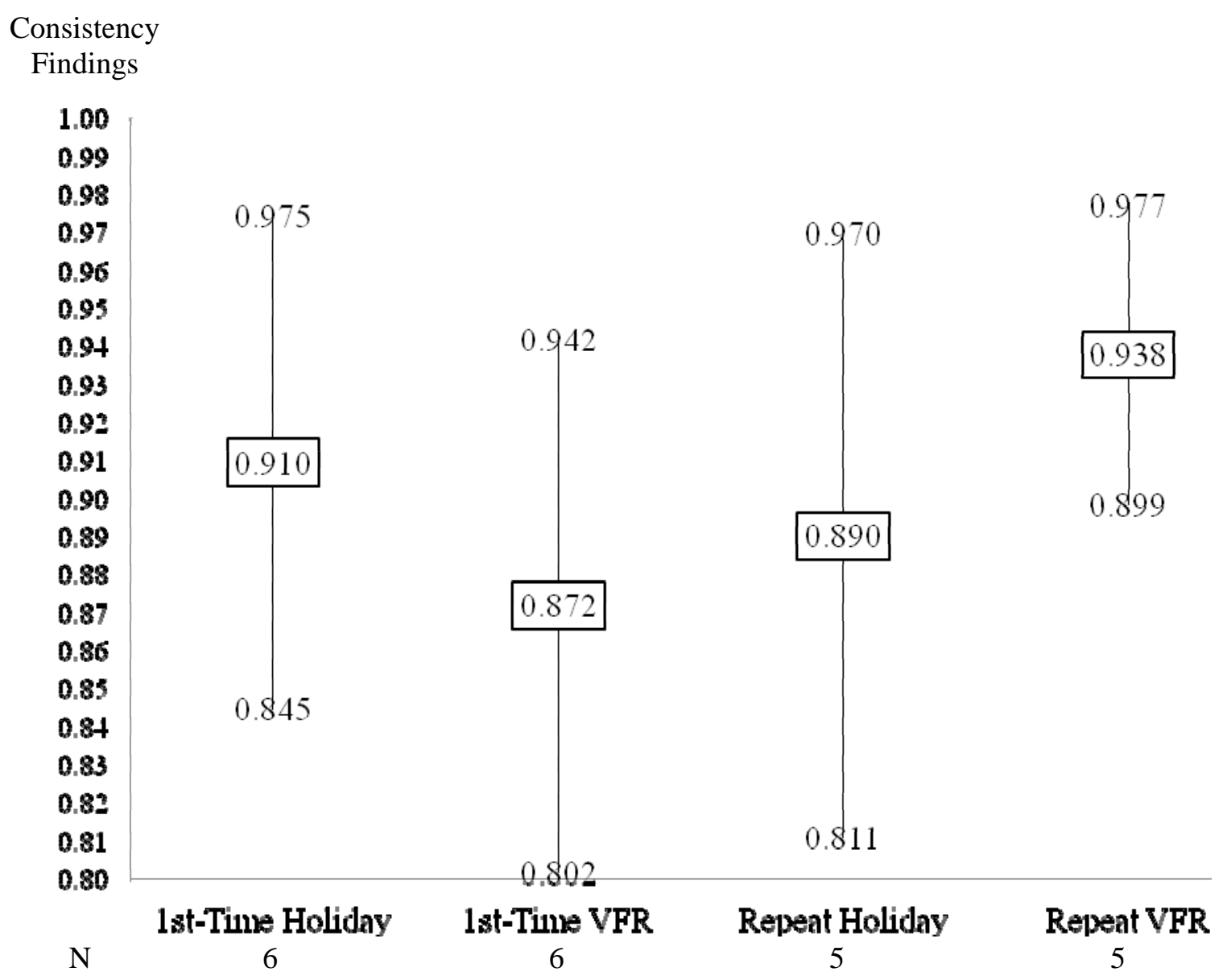


Figure 9: Japanese Cultural Configuration for First-Time Holiday Visitors to Australia by Schwartz's Cultural Theory

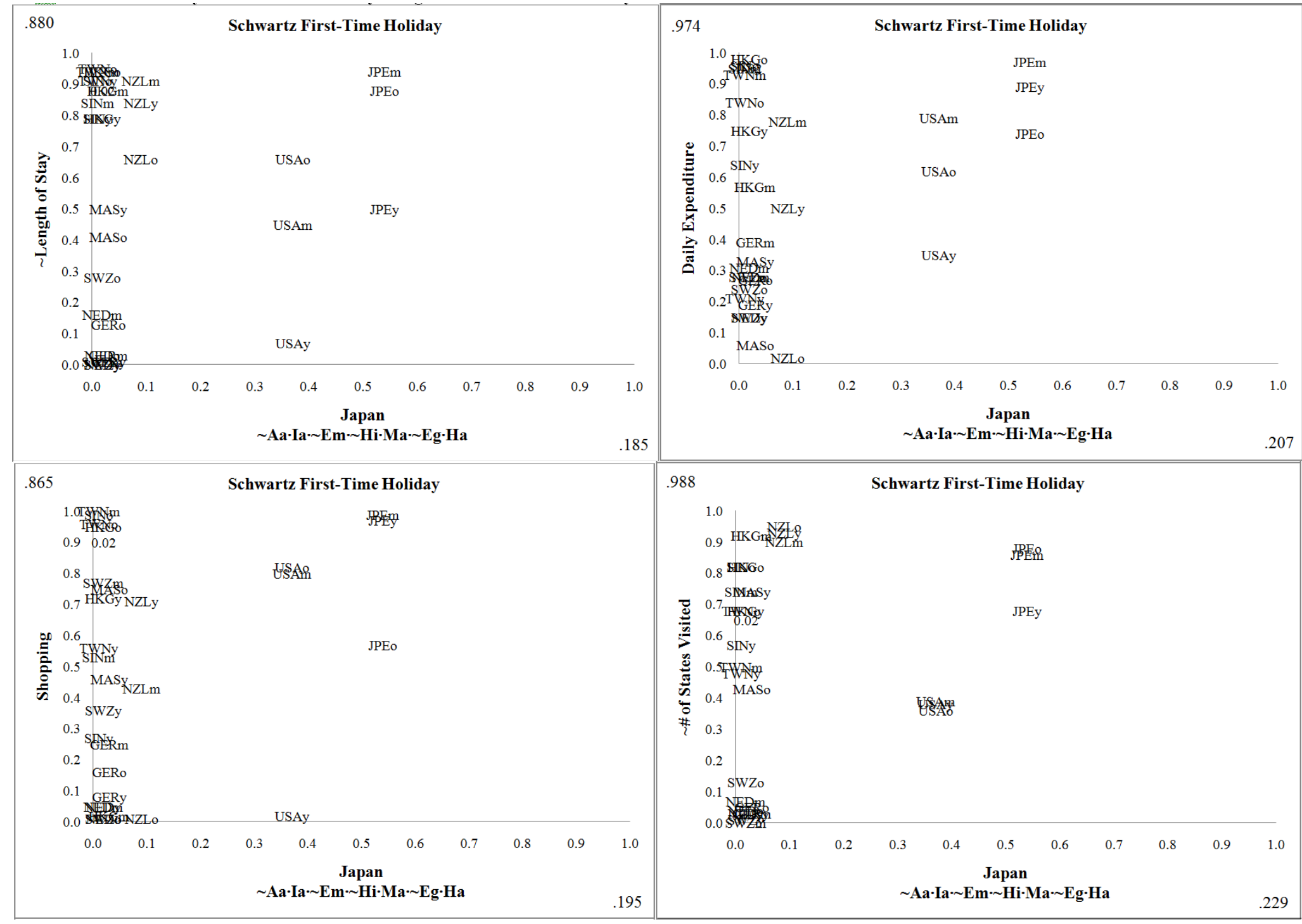


Figure 10: Netherlands Cultural Configuration for First-Time Holiday Visitors to Australia by Schwartz's Cultural Theory

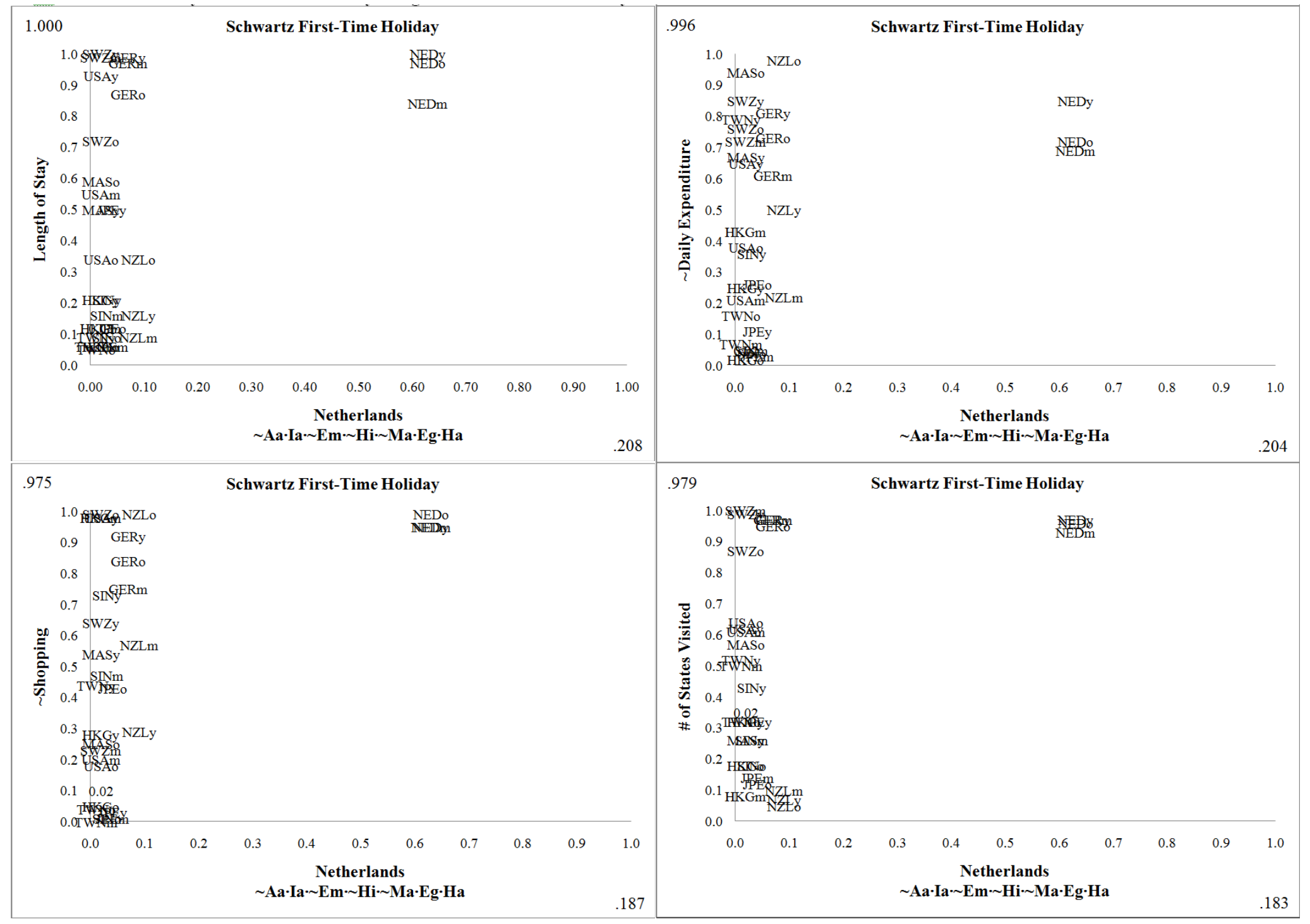


Figure 11: Japanese Cultural Configuration for Visitors to USA by Schwartz's Cultural Theory

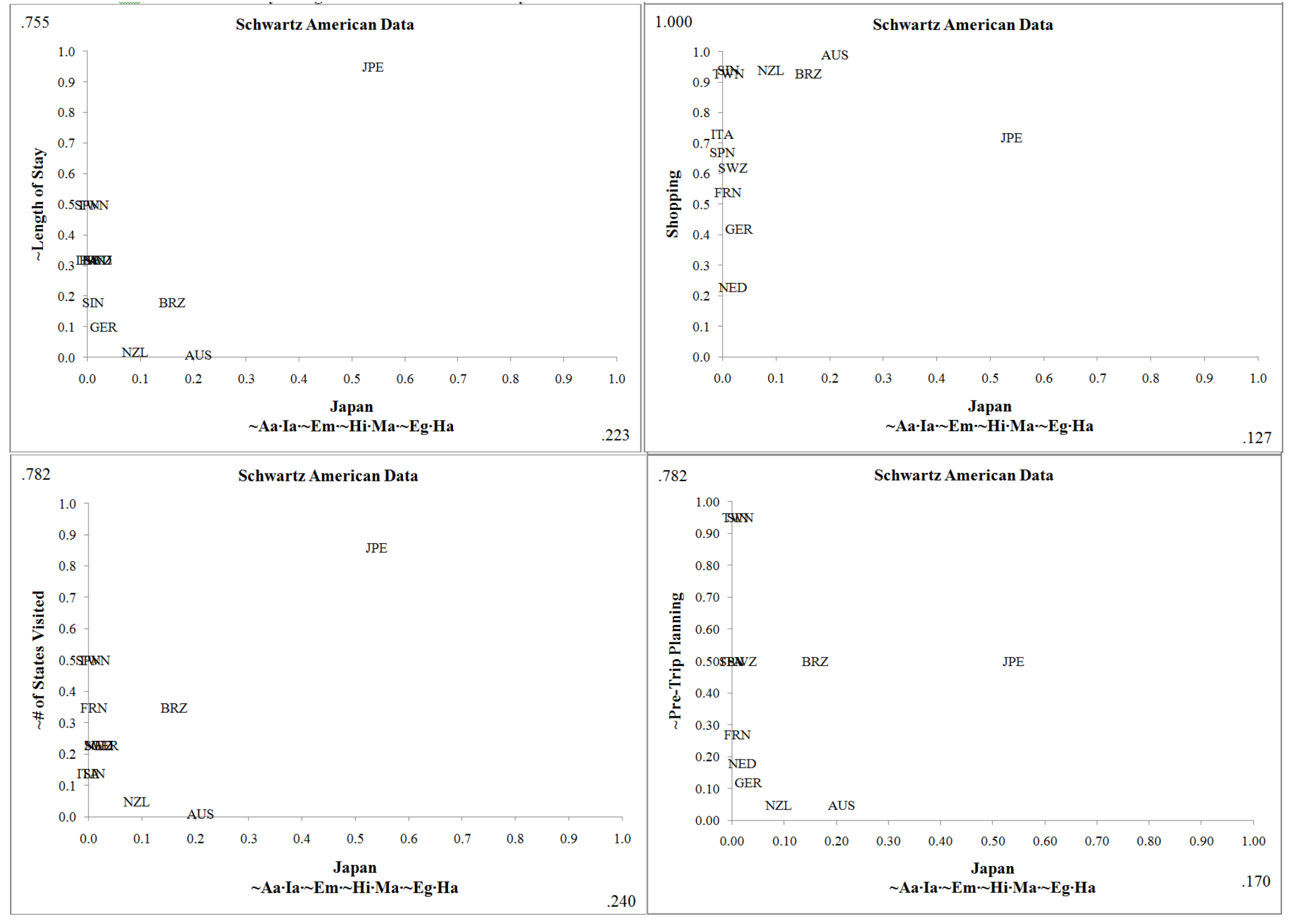


Figure 12: Netherlands Cultural Configuration for Visitors to USA by Schwartz's Cultural Theory

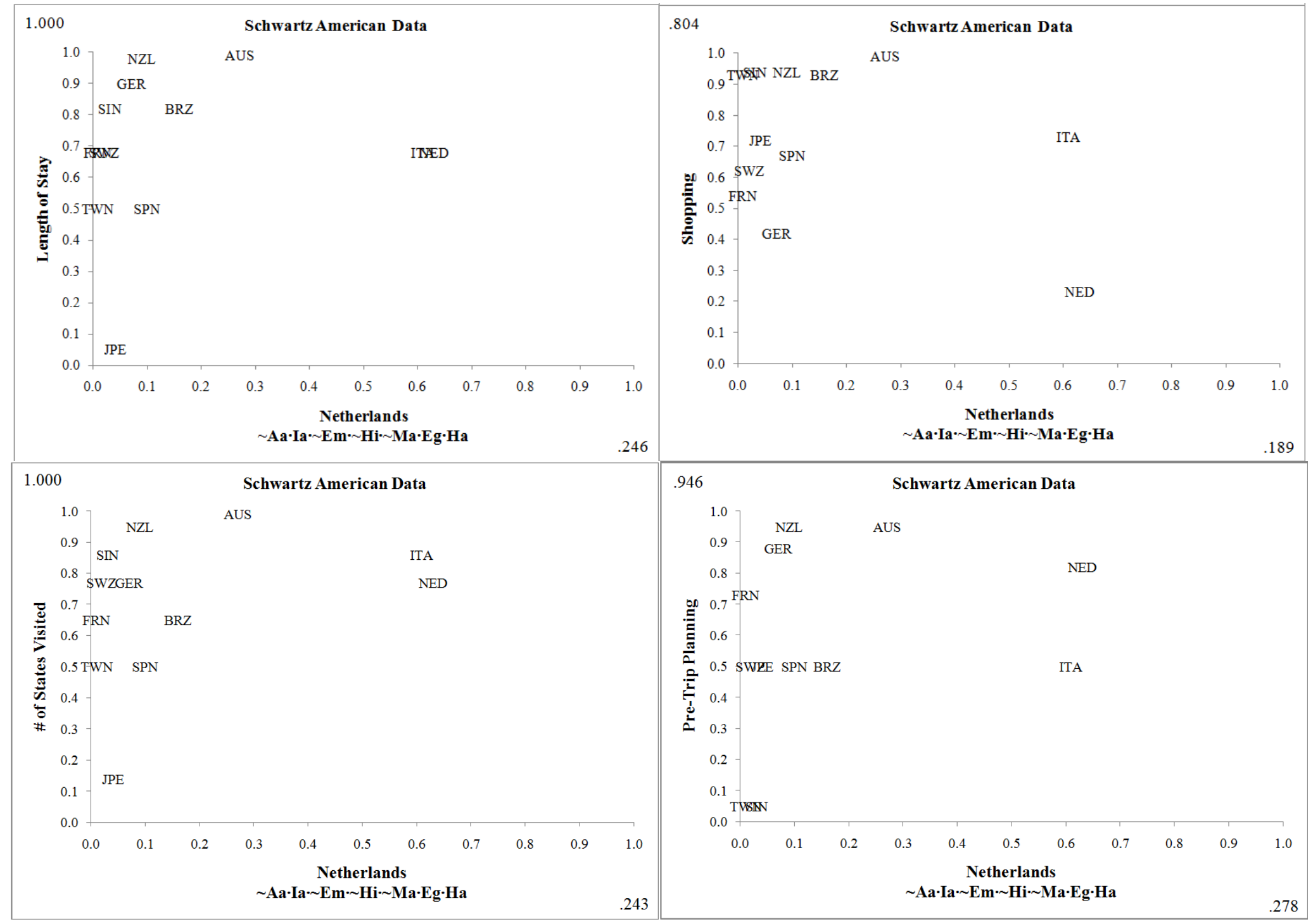


Figure 13: Schwartz's Best Fitting Models for First-Time Holiday Visitors to Australia

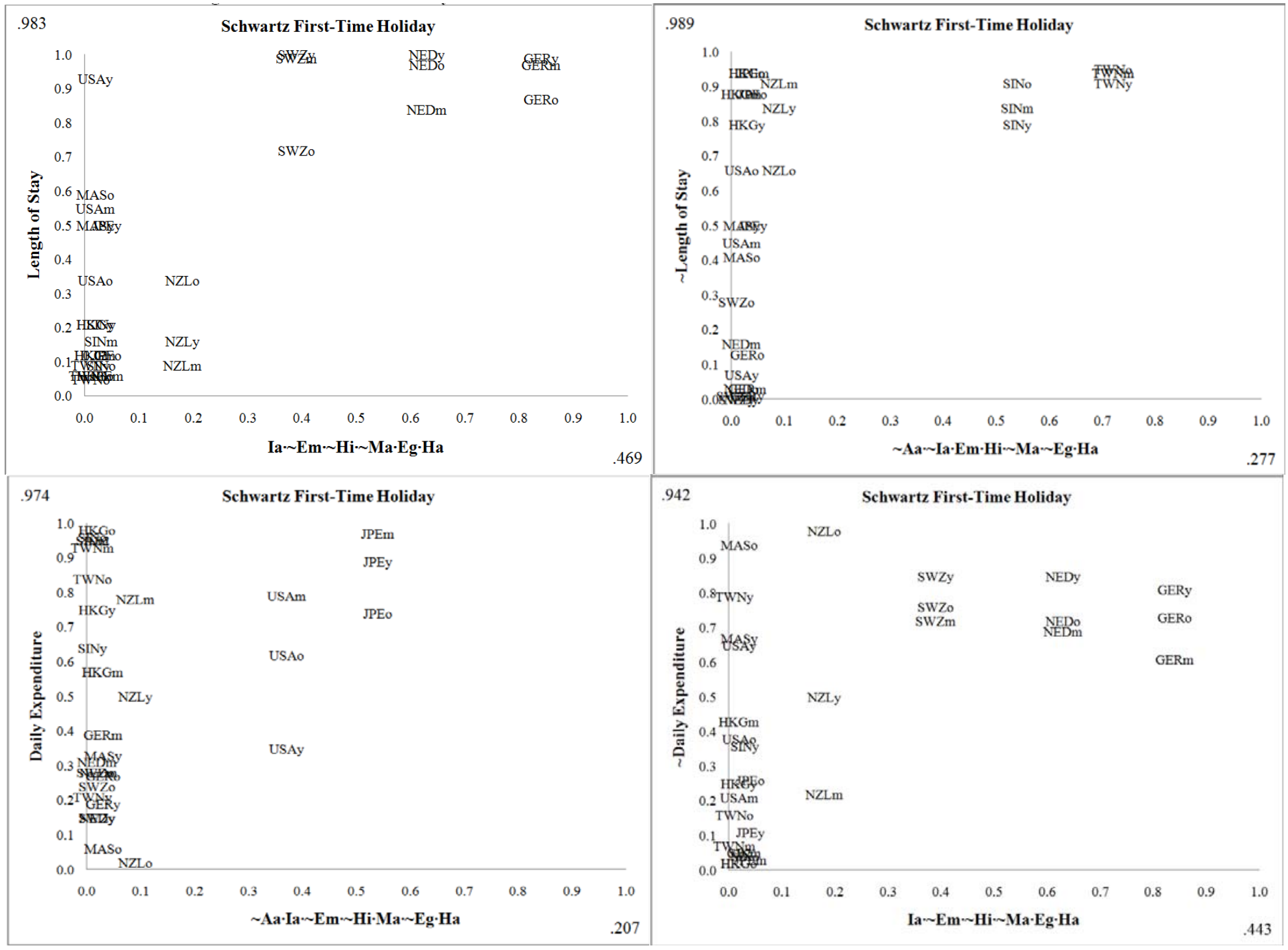


Figure 13: Schwartz's Best Fitting Models for First-Time Holiday Visitors to Australia (Continued)

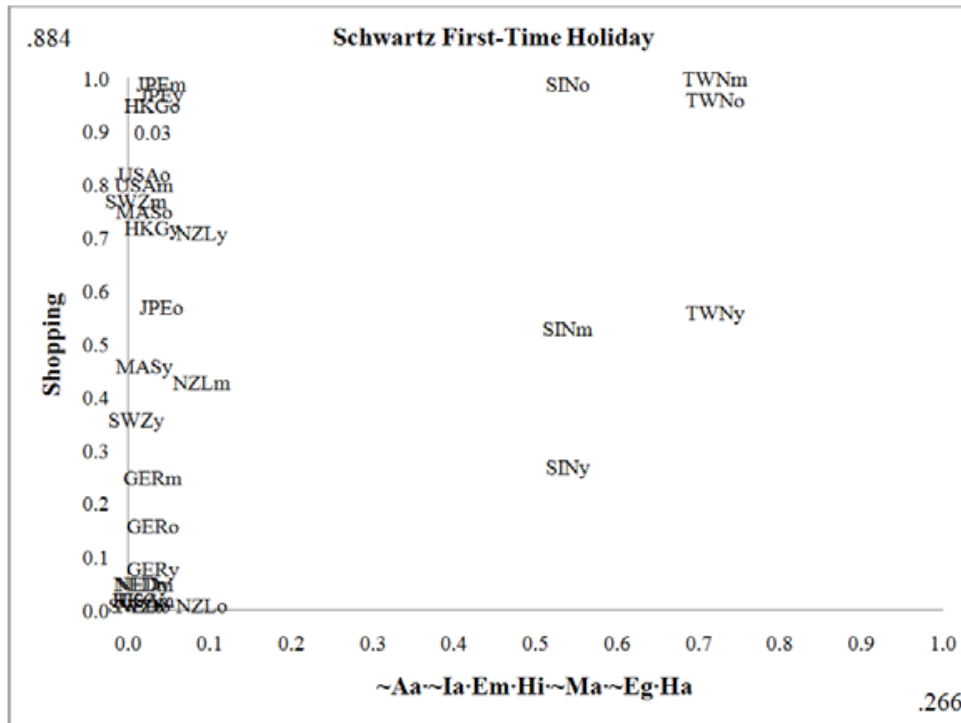

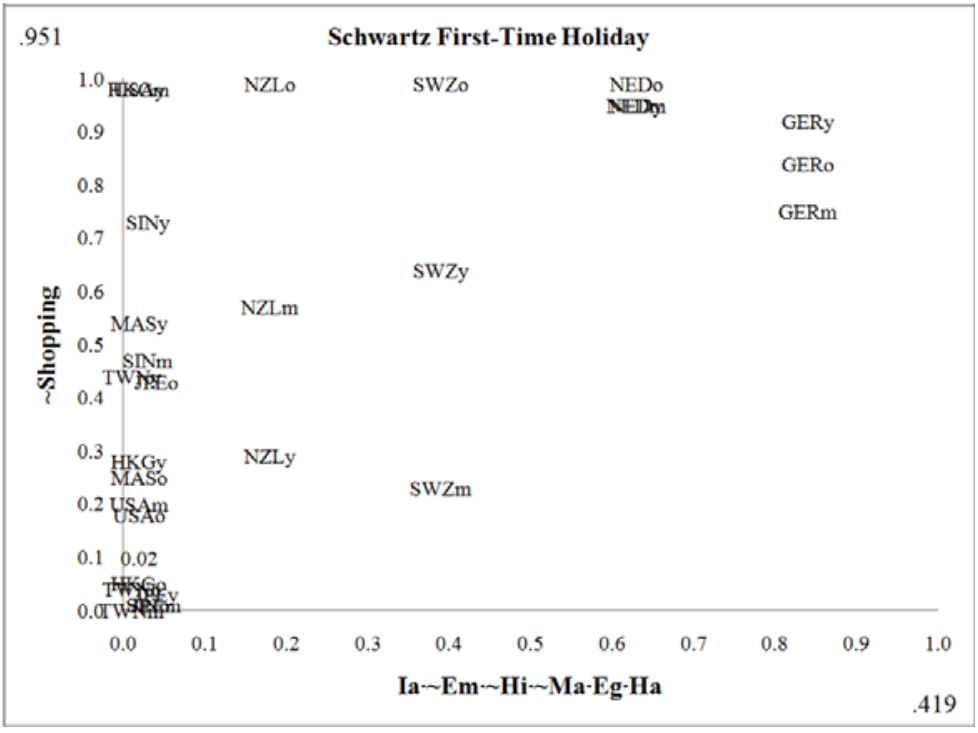

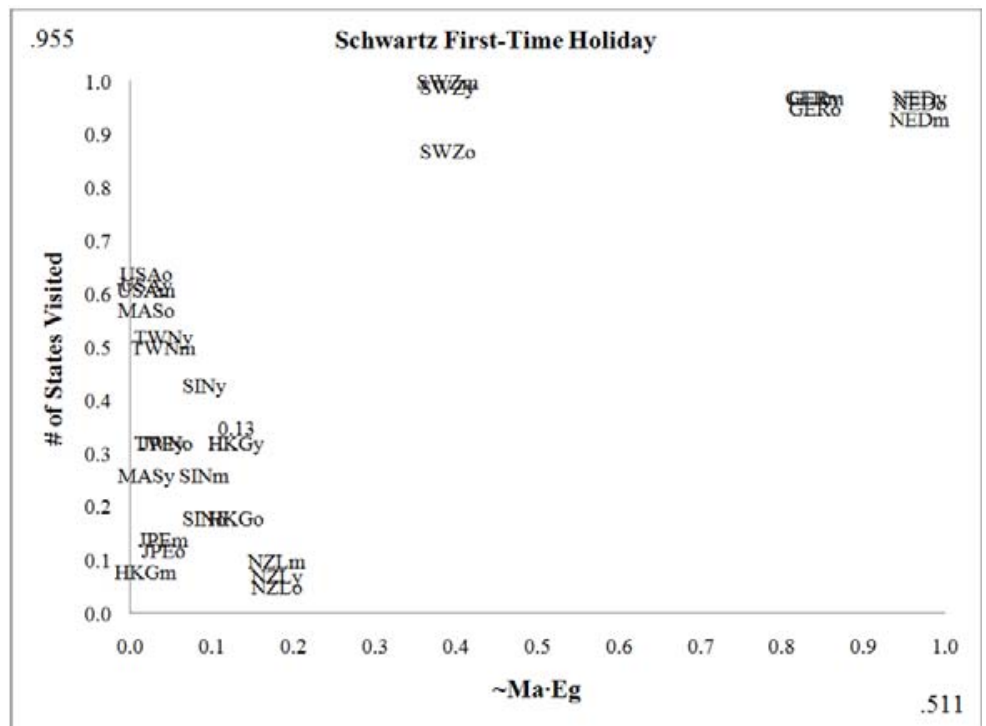

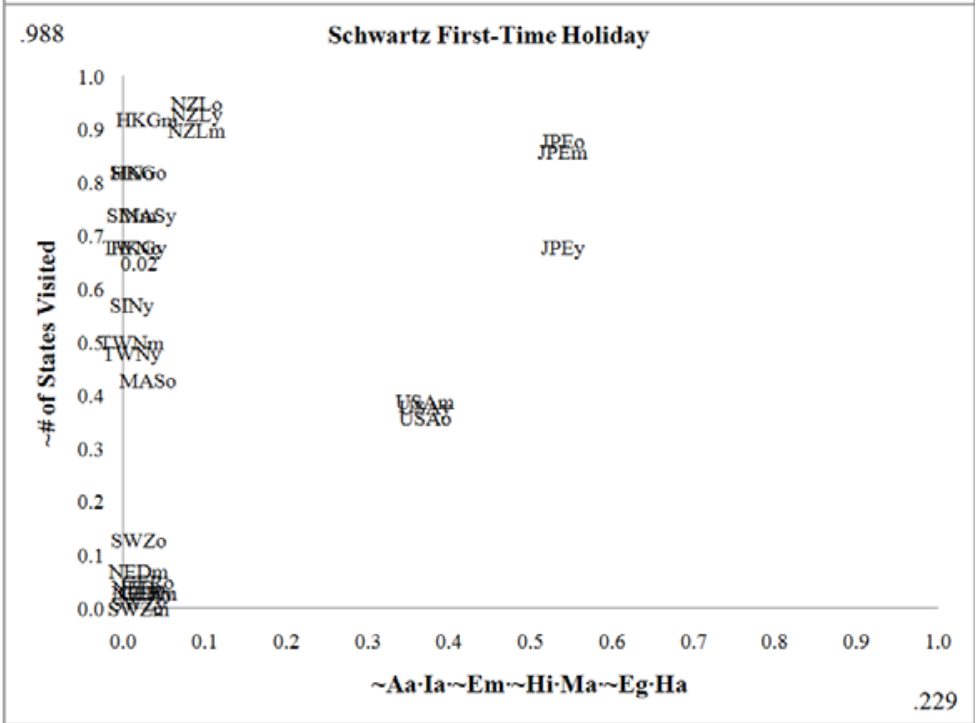


Figure 14: Schwartz's Best Fitting Models for Visitors to USA

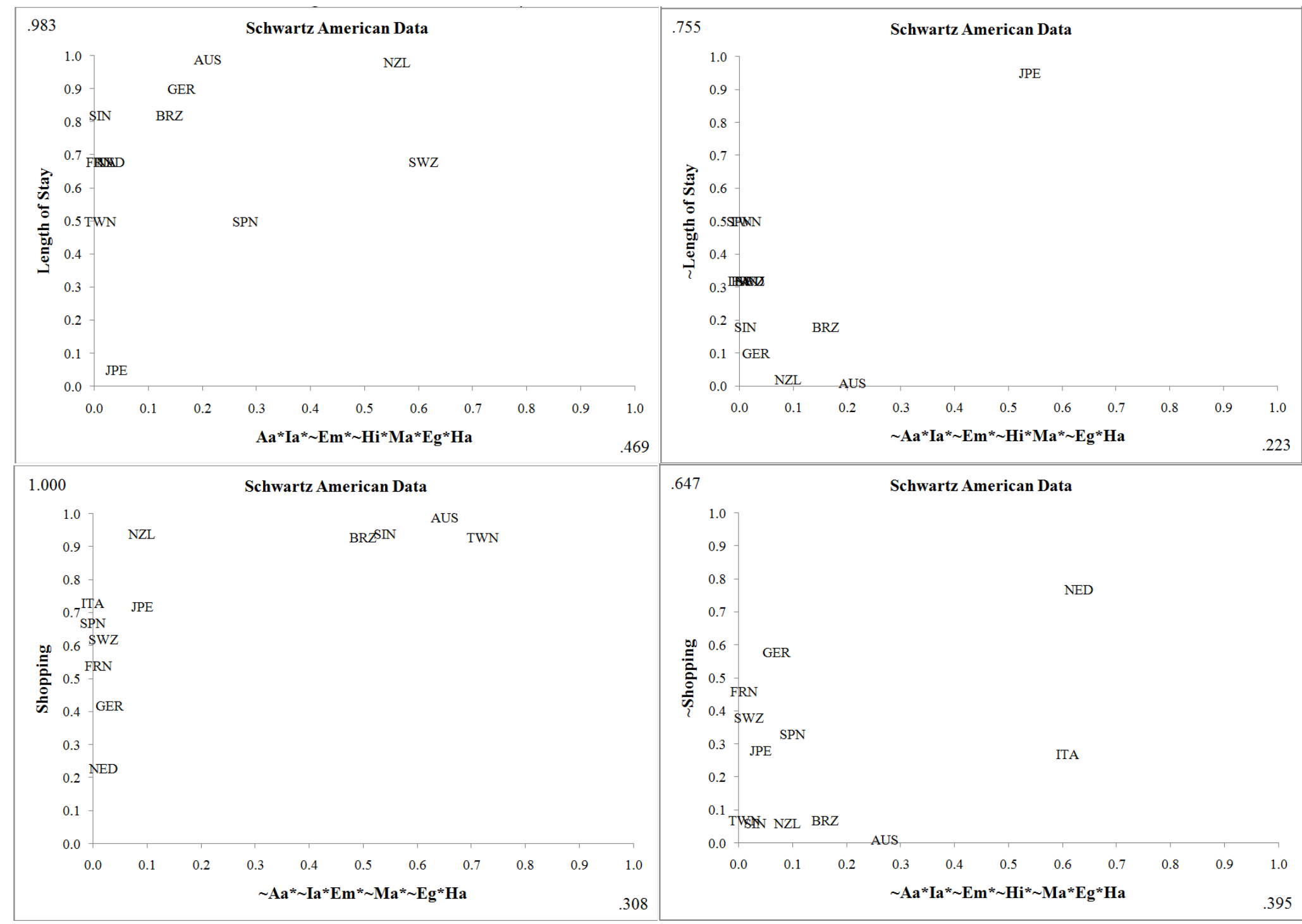


Figure 14: Schwartz's Best Fitting Models for Visitors to USA (Continued)
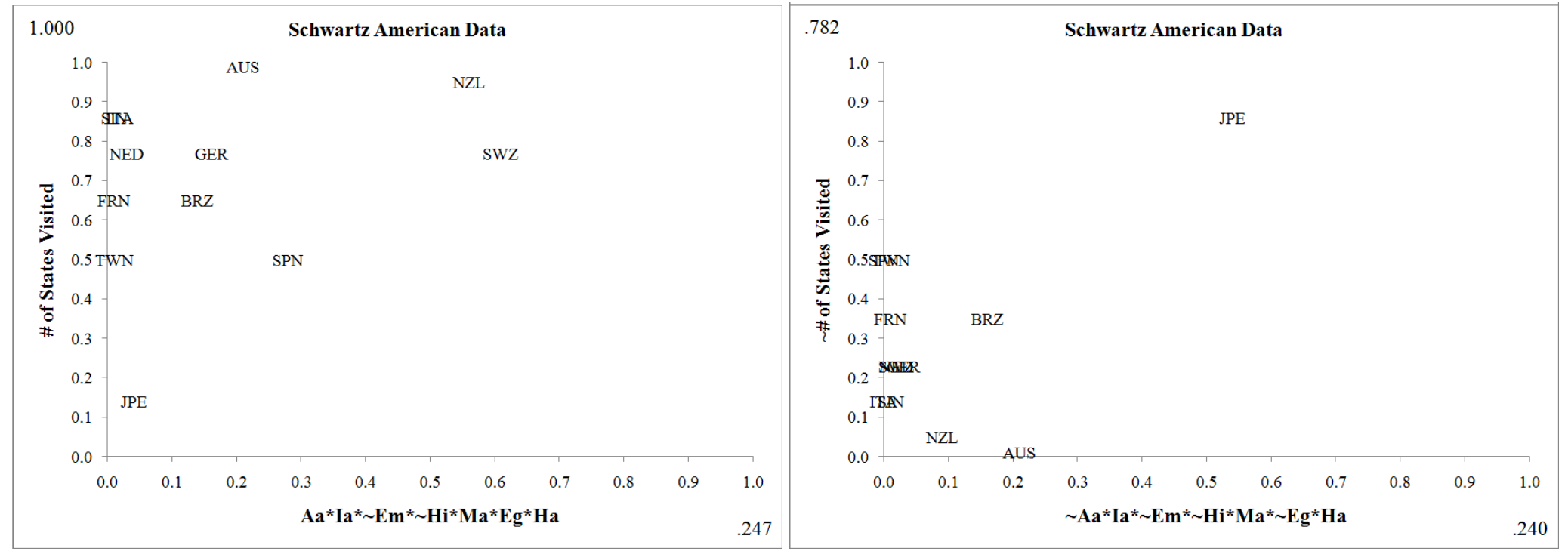

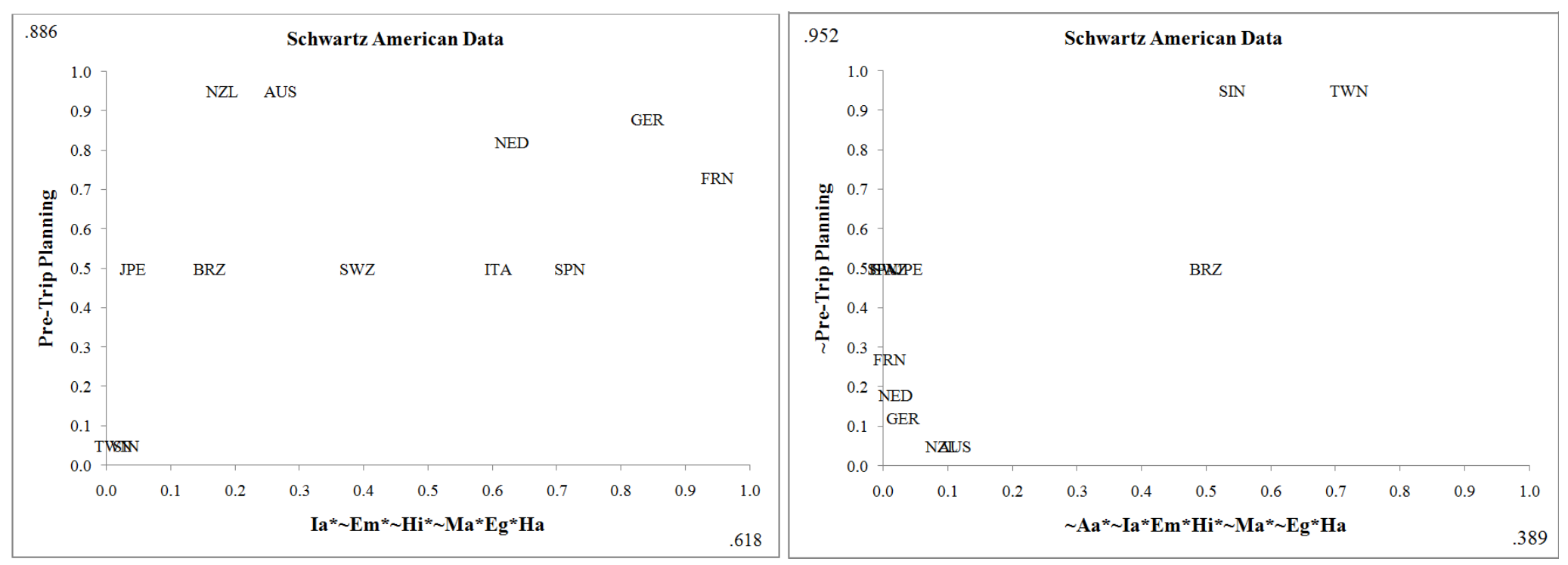


